\title{
Guidelines for the prevention and treatment of venous thromboembolism in non-surgically treated cancer patients
}

\author{
Marek Z. Wojtukiewicz ${ }^{1}$, Ewa Sierko ${ }^{1}$, Witold Tomkowski ${ }^{2}$, Krystyna Zawilska $^{3}$, \\ Anetta Undas ${ }^{4}$, Maria Podolak-Dawidziak ${ }^{5}$, Piotr Wysocki ${ }^{6}$, \\ Maciej Krzakowski ${ }^{7}$, Krzysztof Warzocha $^{8}$, Jerzy Windyga ${ }^{9}$
}

Guidelines for the prevention and treatment of venous thromboembolism (VTE) are aimed to improve patients' safety and quality of life by appropriate prophylaxis and treatment of deep venous thrombosis (DVT) and pulmonary embolism (PE).

These guidelines relate to adult cancer patients treated non-surgically. Recommendations included in those guidelines do not relate to paediatric patients.

The guidelines presented here directed to physicians and other healthcare professionals taking care of mentioned patients: clinical oncologists, haematologists, radiotherapists, pulmonologists, oncological gynaecologists, internal medicine physicians, and GPs.

- Venous thromboembolism (VTE) comprises a serious problem in oncology because it is the most common complication as well as the second most common cause of cancer-related deaths.

- the term "venous thromboembolism" includes the cases of DVT and PE; however, the former is a primary event and the latter is a secondary result.

- Active malignant disease classifies patients to a group with at least moderate risk of VTE.

- D-dimer levels could be increased in cancer patients without concomitant VTE.

- D-dimer levels below cut-off value (negative D-dimer) do not exclude VTE in cancer patients.

- In patients with active malignant disease with clinical symptoms suggesting VTE ultrasound (US) examination of deep veins or computed tomography angiography (angio-CT) should be performed, depending on the symptoms.

- Low-molecular-weight heparins (LMWH) are the drugs of choice in prevention and treatment of VTE in cancer patients.

\footnotetext{
${ }^{1}$ Oncology Clinic, Medical University of Białystok; Oncology Centre of Białystok

${ }^{2}$ National Research Institute for Tuberculosis and Lung Diseases, Warsaw; Polish Foundation Against Thrombosis THROMBOSIS

${ }^{3}$ Karol Marcinkowski Medical University in Poznań; Diagnosis and Treatment Centre INTERLAB in Poznań

${ }^{4}$ Cardilogy Institute, Jagiellonian University Medical College in Kraków; John Paul II Hospital Kraków

${ }^{5}$ Department and Clinic of Haematology, Blood Neoplasms, and Bone Morrow Transplantation, Medical University in Wrocław

${ }^{6}$ Department and Clinic of Oncology, Jagiellonian University Medical College in Kraków

${ }^{7}$ Department of Lung Cancer and Chest Tumour, Maria Skłodowska-Curie Memorial Cancer Centre and Institute of Oncology in Warsaw

${ }^{8}$ Clinic of Haematology, Institute of Haematology and Transfusion Medicine

${ }^{9}$ Department of Disorders of Haemostasis and Internal Medicine, Institute of Haematology and Transfusion Medicine and Polish Society of Clinical Oncology

Working Group on Haemostasis of the Polish Society of Haematology and Transfusion Medicine
} 
- Antithrombotic treatment in cancer patients with DVT does not differ from treatment of cancer patients with PE, except clear indications to thrombolytic therapy.

- Cancer patients with clinical symptoms suggesting PE (dyspnoea, chest pain or tachycardia) are per definition classified into the group of moderate or high clinical probability of PE.

- The majority of PE cases account for embolism, which do not warrant thrombolytic treatment and should be treated with LMWH, UFH, or fondaparinux; LMWHs are the treatment of choice in cancer patients with VTE.

- Cancer patients have increased risk of recurrence of VTE.

- Available evidence does not justify the use of antithrombotic drugs to prolong survival in cancer patients.

NOWOTWORY J Oncol 2016; 66, 4: 326-350

Key words: venous thromboembolism, deep vein thrombosis, pulmonary embolism, cancer patients, prophylaxis, treatment, low-molecular-weight heparin, PE, VTE, DVT, LMWH

\section{Content}

Abbreviations, explanations, and terminology used in this publication .........................................................................328

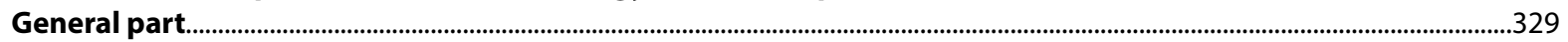

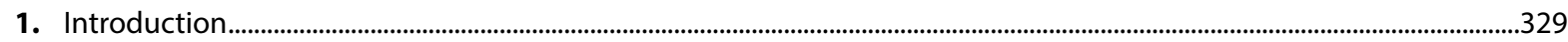

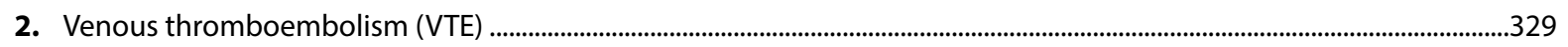

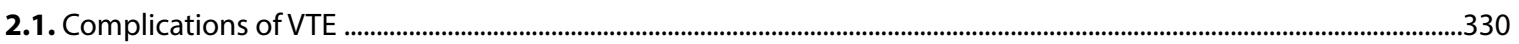

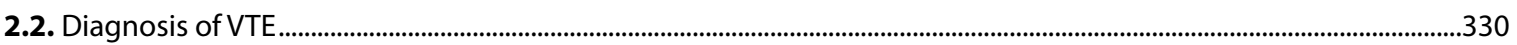

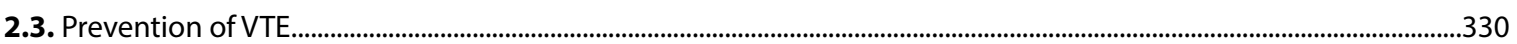

2.4. Treatment of cancer patients with VTE .......................................................................................................................................330

2.5. Antithrombotic drugs in prevention and treatment of patients with VTE ....................................................................330

2.5.1. Low-molecular-weight heparin (LMWH) administered subcutaneously (s.c.) ....................................................330

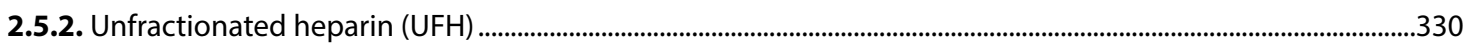

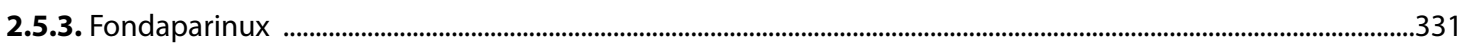

2.5.4. Vitamin K antagonists (VKA) (acenocoumarol and warfarin) ..............................................................................331

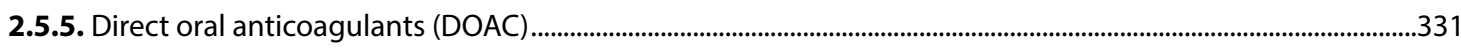

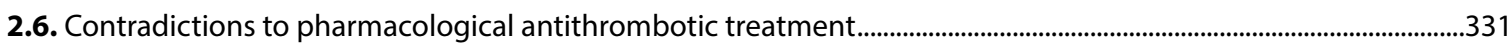

2.7. Non-pharmacological methods for antithrombotic prevention ......................................................................................331

2.8. Thrombolytic drugs ....................................................................................................................................................................................332

2.9. Contradictions to thrombolytic drugs according to 2014 European Society of Cardiology guidelines ..................332

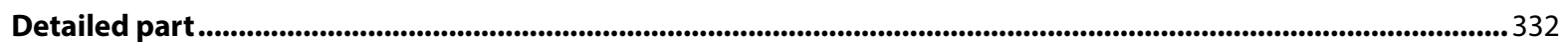

3. Risk factors, symptoms, forms, and diagnosis of VTE ..........................................................................................................332

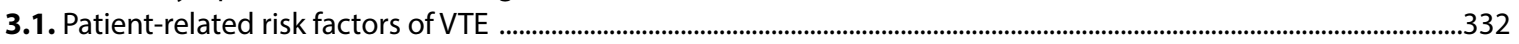

3.2. Cancer-related risk factors of VTE ...........................................................................................................................................332

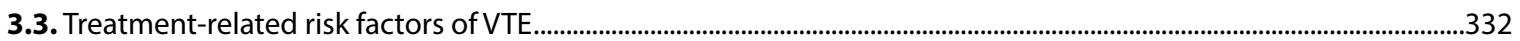

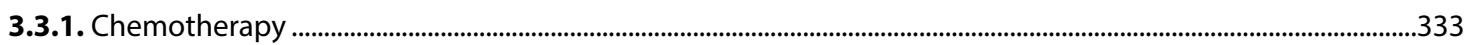

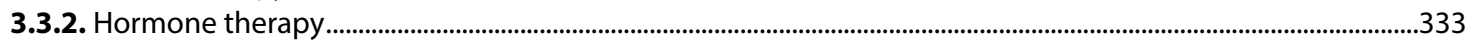

3.3.3. Anti-angiogenic treatment .........................................................................................................................................333

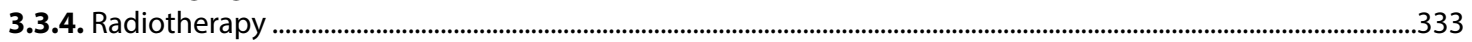

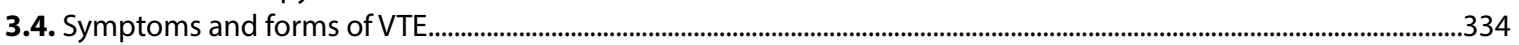

3.4.1. Lower extremities VTE ..................................................................................................................................................334

3.4.2. Upper extremities VTE................................................................................................................................................334

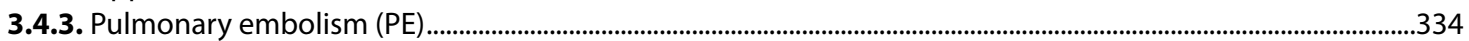

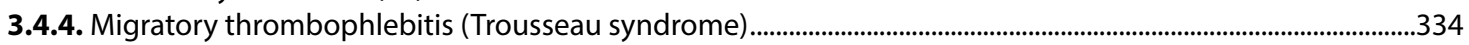

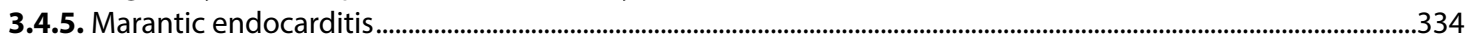

3.4.6. Hepatic vein thrombosis (Budd-Chiari syndrome) ....................................................................................................334

3.4.7. Thrombosis in the portal vein, splenic vein, mesenteric vein, and renal veins......................................................334

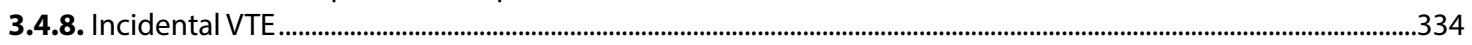

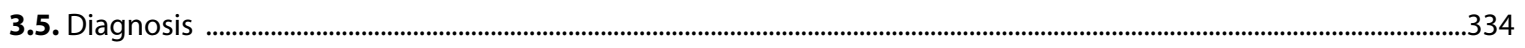

3.6. Searching for cancer in patients with VTE or PE — occult malignancy .......................................................................335

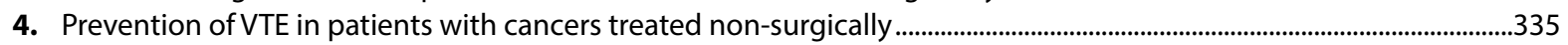

4.1. Prevention of VTE in hospitalised, medically ill cancer patients ........................................................................................335

4.2. Prevention of VTE in outpatients undergoing non-surgical anticancer treatment .......................................................336 
4.3. Antithrombotic prevention in patients with indwelling central venous catheter

4.4. Prevention of VTE in patients with concomitant thrombocytopaenia .............................................................................337

4.5. Antithrombotic prevention in patients with concomitant renal insufficiency ..............................................................338

4.6. Antithrombotic prevention in terminally ill cancer patients treated in hospices ..........................................................338

4.7. Prevention of VTE in pregnant women diagnosed with cancer .......................................................................................338

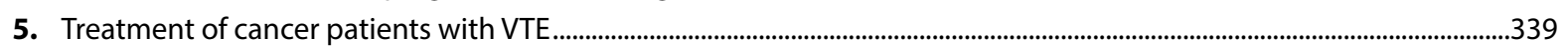

5.1. Initial treatment of cancer patients with VTE or PE with no need for thrombolytic therapy ......................................339

5.2. Initial treatment of cancer patients with $P E$ with need for thrombolytic therapy .......................................................340

5.3. Long-term and chronic treatment of cancer patients with VTE ..................................................................................341

5.4. Treatment of cancer patients with VTE and concomitant thrombocytopaenia .............................................................343

5.5. Treatment of cancer patients with VTE and renal insufficiency ....................................................................................344

5.6. Treatment of pregnant women with coincidence of cancer and VTE …........................................................................345

5.7. Treatment of recurrent VTE during antithrombotic treatment ....................................................................................346

6. Using of antithrombotic treatment in order to prolong overall survival in cancer patients ................................................346

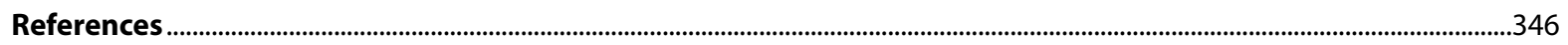

\section{Abbreviations, explanations, and terminology used in this publication (in alphabetical order)}

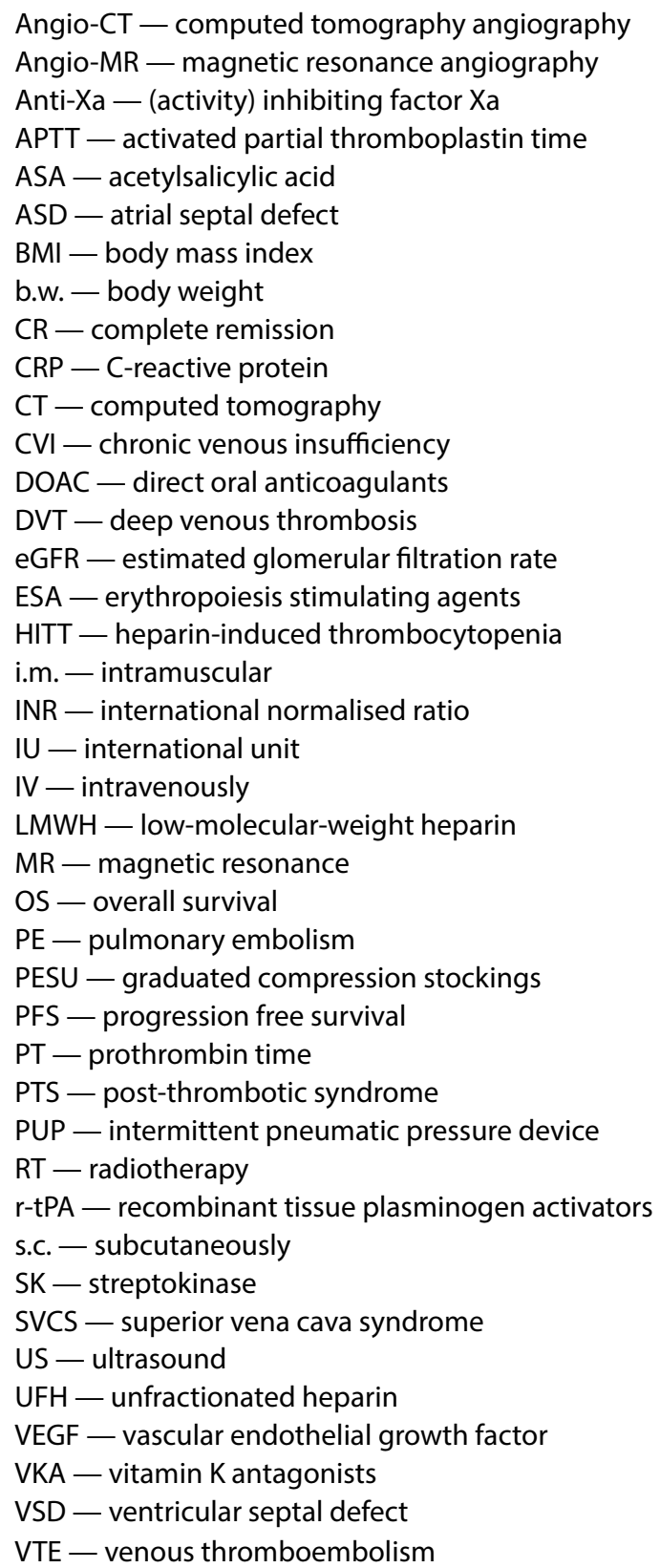




\section{General part \\ 1. Introduction}

Venous thromboembolism (VTE) comprises a serious problem in oncology because it is the most common complication as well as the second most common cause of cancer-related deaths [1-5]. The risk of VTE is 4-6-fold higher in cancer patients as compare to the general population [1-5]. Population-based trials revealed that year-year cumulative incidence of VTE is between $0.8-8 \%$ [5]. Moreover, VTE is 4-13-fold more frequent in patients with advanced cancer compared to the patients with early stage cancers [5]. It mainly affects patients with brain malignant tumours, pancreatic, lung, gastric, endometrial, bladder, and renal cancers [5]. Clinical symptoms of VTE are noted in approximately $30 \%$ of pancreatic and lung cancer patients $[3,4]$. Of note, in cancer patients with VTE the risk of recurrent deep venous thrombosis (DVT) and/or pulmonary embolism (PE) is threefold higher than in non-cancer patients with VTE $[6,7]$. VTE recurrence risk is highest during the first few months after cancer diagnosis and can continue for many years after the first thrombosis episode [5]. During chemotherapy the risk ofVTE is increased several times as compared with non-cancer individuals, especially in patients with pancreatic and gastric cancer [5, 8].

It should be added that VTE itself, antithrombotic treatment, as well as VTE complications adversely affect the quality of life of cancer patients. Additionally, the risk of death in cancer patients with VTE is higher than in those without such a complication, which results from higher cancer aggressiveness and interaction of cancer with haemostasis components [7, 9]. It was also noticed that in patients with pancreatic cancer treated with chemotherapy occurrence of clinically overt VTE was associated with worsening of responses and shortening of progression-free survival (PFS) and overall survival (OS) [7]. In the group of cancer patients with VTE deaths are eight-fold more frequent than in patients with VTE during other underlying diseases [7]. It should be also highlighted that the risk of VTE in cancer patients increases as more co-morbidities occur $[3,4]$.

Despite the common prevalence of VTE and its unfavourable influence on prognosis in cancer patients treated non-surgically, this problem is still underestimated by treating physicians $[10,11]$. Thereby, inappropriate prevention and treatment could be a consequence. There are an increasing number of patients with cancer-related VTE, possibly due to higher mean age of patients, longer OS resulting from progress of anticancer treatment, as well as better diagnostic procedures [12]. These are the reasons for Polish experts' and scientific societies' initiative to develop guidelines to help physicians to identify cancer patients with increased VTE risk in daily clinical practice, and to use optimal prevention and appropriate treatment of VTE as needed. For this purpose, available medical literature from the last 20 years was analysed, including published international and Polish guidelines regarding this topic:

- ISTH (International Society on Thrombosis and Haemostasis) [13, 14];

- ASCO (American Society of Clinical Oncology) [8, 15-17];

- ESMO (European Society for Medical Oncology) [18];

- NCCN (National Comprehensive Cancer Network) [19, 20];

- ACCP (American College of Chest Physicians) [21, 22];

- Polish guidelines [23-25];

- AIOM (Italian Association of Medical Oncology) [26];

- French National Guidelines [27] and French National Federation of Cancer Centres [28];

- ESC (European Society of Cardiology) [29];

- International Consensus Statement [30].

The abovementioned guidelines use a grading of strength and reliability of evidence associated to a particular topic based on the GRADE (Grading of Recommendations Assessment Development and Evaluation Scale) system and ACCP guidelines published in 2012 and 2016 [31-33]. Guidelines were assessed as either strong [1] or weak [2]. The quality of data from published studies using EBM (evidence-based medicine) rules, being a basis for guidelines, were described and marked with a letter (A), (B), or (C). Guidelines marked with letter (A) are manly based on randomised clinical trials (RCT) with unambiguous results, and further studies probably will not elicit any changes. The letter (B) indicates that further studies could possibly influence the changes of guidelines, whilst the letter $(C)$ indicates low quality of available data, resulting mainly from scarce RCT, so further studies are very likely to change the guidelines. They are three levels of recommendation importance distinguished in the presented guidelines:

- $1 \mathrm{~A}$ - strong recommendation, high-quality evidence;

- $1 \mathrm{~B}$ - strong recommendation, moderate-quality evidence;

- $1 \mathrm{C}$ - strong recommendation, low- or very low-quality evidence;

- $2 \mathrm{~A}$ - weak recommendation, high-quality evidence;

- $2 \mathrm{~B}$ - weak recommendation, moderate-quality evidence;

- $2 \mathrm{C}$ - weak recommendation, low- or very low-quality evidence.

Guidelines without brackets (with very few publications of low reliability, including ambiguous expert opinions) were considered by experts and scientific societies as currently suggested clinical management. Recommendations based on current literature could differ from current summaries of product characteristics.

\section{Venous thromboembolism (VTE)}

The term "venous thromboembolism"includes the cases of DVT and PE; however, the former is a primary event and 
the latter is a secondary result. In approximately half of patients DVT is asymptomatic. In half of patients with DVT of the proximal part, asymptomatic (clinically silent) PE could be diagnosed. In many patients PE leading to death is the very first and only sign of VTE [34].

\subsection{Complications of VTE}

Acute complications of DVT could cause PE, and in patients with ventricular septal defect (VSD) or atrial septal defect (ASD) even stroke or peripheral embolism.

Post-thrombotic syndrome (PTS) is a chronic complication of DVT, occurring in $20-50 \%$ of patients with DVT, often leading to chronic venous insufficiency (CVI), which manifests as pain of extremities, skin discoloration, and varicosities, and in the most advanced cases with hard-toheal ulcerations.

The outcome of acute PE can be fatal in 2-8\% of patients. In $2-4 \%$ of patients, high risk or recurrent PE could lead to development of chronic thromboembolic pulmonary hypertension, which manifests as right ventricular heart failure, dyspnoea, oedema of lower extremities, and impaired exercise tolerance. This complication is associated with poor prognosis.

Chronic complications of VTE are an important clinical problem due to their incidence and high cost of diagnostic and therapeutic procedures. Additionally, in advanced stages they cause long-term inability to work and decreased quality of life [34].

\subsection{Diagnosis of VTE}

The patient's physical examination should consider risk factors (subunit 3.1), symptoms related to location of disease (subunit 3.4), and in the case of suspicious of PE - previous or recent episodes of DVT.

Active malignant disease classifies patients to a group with at least moderate risk of VTE. Thus, cancer patients with clinical symptoms of VTE warrant immediate diagnostic tests, e.g. ultrasound (US) examination of deep veins in case of DVT symptoms and computed tomography angiography (angio-CT) of pulmonary arteries and US of deep veins in case of PE suspicious [34].

\subsection{Prevention of VTE}

Occurrence of VTE in cancer patient worsens the prognosis and decreases health-related quality of life [35]. Appropriate antithrombotic prevention used in cancer patients with high risk of VTE in non-surgical departments and in some outpatient patients could decrease the incidence of VTE and thereby mortality due to PE $[6,36-38]$.

\subsection{Treatment of cancer patients with VTE}

Antithrombotic treatment of cancer patients with VTE is divided into three phases (Figure 1):

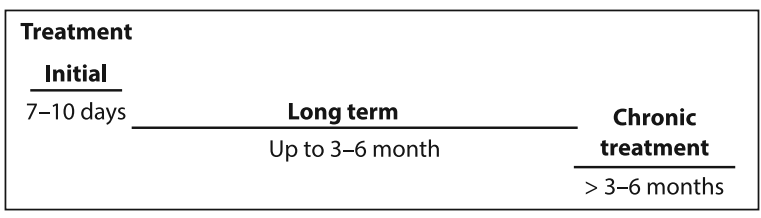

Figure 1. Phases of antithrombotic treatment of cancer patients with venous thromboembolism

— initial treatment - 7-10 days;

- long-term treatment - up to 3-6 months;

- chronic treatment - after 3-6 months [23].

Pulmonary embolism is divided into three categories: low, moderate and high risk or (much simplified) into categories that warrant (high risk) or do not warrant thrombolytic treatment.

\subsection{Antithrombotic drugs in prevention and treatment of patients with VTE}

2.5.1. Low-molecular-weight heparin (LMWH) administered subcutaneously (s.c.)

Dosing of LMWH in prevention of VTE:

- dalteparin 5000 IU every 24 hours;

- enoxaparin $40 \mathrm{mg}$ every 24 hours;

- nadroparin $3800 \mathrm{IU}$ every 24 hours, in patients of body weight over $70 \mathrm{~kg} 5700$ IU every 24 hours [39].

Dosing of LMWH during initial treatment of VTE (in al-

phabetical order):

- dalteparin (100 IU/kg every 12 hours or $200 \mathrm{lU} / \mathrm{kg}$ every 24 hours) - during initial treatment dosing every 12 hours is preferred;

- enoxaparin ( $1 \mathrm{mg} / \mathrm{kg}$ every 12 hours or forte form 1.5 $\mathrm{mg} / \mathrm{kg}$ every 24 hours);

- nadroparin $(86 \mathrm{lU} / \mathrm{kg}=0.1 \mathrm{ml} / \mathrm{kg}$ b.w. every 12 hours or $171 \mathrm{lU} / \mathrm{kg}$ b.w. $=0.1 \mathrm{ml} / \mathrm{kg}$ every 24 hours) [39].

\subsubsection{Unfractionated heparin (UFH)} Dosing of UFH in prevention of VTE:

- 5000 IU every 8 hours IV or s.c.

- Dosing of UFH during initial treatment of VTE:

- initial dose of UFH (bolus) could be administered IV and should be adjusted to body weight and amount to 80 IU/kg b.w. (although not lower than 5000 IU), then IV with APTT monitoring (during continuous infusion APTT should be prolonged 1.5-2.5-fold as compare to control, which reflects a drug serum concentration of 0.3-0.6 IU of anti-Xa activity);

- the infusion rate is based on body weight and amounts to $18 \mathrm{IU} \mathrm{UFH/kg} \mathrm{b.w./hour,} \mathrm{provided} \mathrm{that} \mathrm{it} \mathrm{is} \mathrm{not} \mathrm{lower}$ than $1250 \mathrm{IU} /$ hour;

- UFH could be also administered s.c.; in those cases UFH is initially administered IV in the dose of $5000 \mathrm{IU}$ in bo- 
lus and then s.c. $17500 \mathrm{IU}$ every 12 hours with APTT monitoring;

- during establishing of UFH dose Reschke normograms could be helpful [40];

- although the risk of heparin-induced thrombocytopaenia (HITT) during treatment with UFH is low, from the $4^{\text {th }}$ to $14^{\text {th }}$ day of UFH therapy or to UFH therapy termination, platelets count should be assessed every 2-3 days. Patients previously treated with heparin could warrant earlier assessment of platelet count as well as more frequent monitoring of this parameter considering the possibility of earlier occurred HITT;

- UFH should be administered for 5-7 days, and in justified cases therapy should be prolonged to 10 days.

\subsubsection{Fondaparinux}

Dosing of fondaparinux in prevention of VTE:

$2.5 \mathrm{mg}$ every 24 hours s.c.

Dosing of fondaparinux in the treatment of VTE: every 24 hours s.c. in doses:

- in patients with body weight below $50 \mathrm{~kg}-5 \mathrm{mg}$;

- in patients with body weight between $50-100 \mathrm{~kg}$ $-7.5 \mathrm{mg}$;

- in patients with body weight over $100 \mathrm{~kg}-10 \mathrm{mg}$.

\subsubsection{Vitamin K antagonists (VKA) (acenocoumarol} and warfarin)

VKA are used orally with monitoring of prothrombin time (PT) converted into the INR value (INR value should be in the range between 2.0-3.0; in patients with higher bleeding risk INR should be about 2.0).

In patients taking VKA in stable dose (after its establishment) it is suggested to measure INR not less frequently than every four weeks. In patients taking VKA in stable dose with INR values significantly varying, more frequent INR assessment is suggested - every 1-2 weeks [2C]. Patients should receive dietary counselling about vitamin $\mathrm{K}$ levels in food products and possible drug-drug interactions, especially with over-the-counter (OTC) drugs. For stability of vitamin $\mathrm{K}$ treatment a balanced diet is needed with similar daily dose of vitamin $\mathrm{K}$.

\subsubsection{Direct oral anticoagulants (DOAC)}

Currently they are not recommended in cancer patients with VTE. LMWH is a drug of choice in cancer patients using DOAC for other indications, e.g. cardiological, especially atrial fibrillation, and those who experienced VTE, because such incidence suggests failure of anticoagulation. LMWHs are not recommended in chronic stroke prevention in patients with atrial fibrillation.

- Oral direct thrombin inhibitors:

- dabigatran.

- Oral direct inhibitors of factor Xa:

- rivaroxaban, apixaban, edoxaban.
Table I. Point scale for bleeding risk assessment in hospitalised, acutely ill patients with no need for surgical intervention, with own modification (so called IMPROVE scale) [41]

\begin{tabular}{lc}
\hline Bleeding risk factor & $\begin{array}{c}\text { Number of } \\
\text { points }\end{array}$ \\
\hline eGFR $\geq 60 \mathrm{ml} / \mathrm{min} / \mathrm{m}^{2}$ & 1 \\
Male gender & 1 \\
Age 40-84 years & 1 \\
Malignant disease & 2 \\
Rheumatic disease & 2 \\
Central vein catheter & 2 \\
Hospitalisation in intensive care unit or & 2.5 \\
cardiological intensive care unit & 2.5 \\
eGFR < 30 ml/min/m² & 2.5 \\
Hepatic insufficiency (INR > 1.5) & 3.5 \\
Age $\geq 85$ years & 4 \\
Platelets count < 50 G/l & 4 \\
Bleeding during last three months before & 4.5 \\
hospitalisation & $\mathbf{7}$ \\
Active gastric and duodenal peptic ulcer disease & \\
High bleeding risk & 4.5 \\
\hline
\end{tabular}

eGFR - estimated glomerular filtration rate; INR — international normalised ratio

\subsection{Contradictions to pharmacological antithrombotic treatment}

Contraindications to antithrombotic treatment should be considered in each case of decision making about the use of those drugs in cancer patients.

Absolute contraindications include the following:

- clinically important haemorrhagic diathesis;

- active bleeding;

- dissecting aortic aneurysm;

- haemorrhagic stroke (two weeks to three months from incidence, depending on thromboembolic risk);

- hypertensive crisis;

— infective endocarditis;

- HITT — only related to UFH and LMWH.

- Relative contraindications include the following:

- active peptic ulcer disease;

- primary or metastatic neoplasm of central nervous system;

- severe hepatic insufficiency with tendency to bleed. IMPROVE scale facilitates assessment of bleeding risk (Table I) [41].

\subsection{Non-pharmacological methods for antithrombotic prevention}

During use of pharmacological antithrombotic prevention in patients immobilised due to acute disease it is recommended to concomitantly use mechanical prevention methods with graduated compression stockings (PESU) or intermittent 
pneumatic pressure devices (PUP). Mechanical prevention is also recommended in the case of contraindication to pharmacological antithrombotic prevention.

\subsection{Thrombolytic drugs}

Dosing in systemic administration during treatment of patients with $\mathrm{PE}$ :

- alteplase (rt-PA):

- standard scheme: 100 mg IV during two hours;

- accelerated scheme (rarely used): $0.6 \mathrm{mg} / \mathrm{kg}$ b.w. (max. $50 \mathrm{mg}$ ) during 15 minutes;

- streptokinase (SK):

- accelerated scheme (preferred ${ }^{\mathrm{a}}$ ): $1.5 \mathrm{mln}$ IU IV during 2 hours;

- standard scheme: 250,000 IU IV during 30 minutes, then 100,000 IU/hour during 12-24 hours;

- urokinase:

- accelerated scheme: $3 \mathrm{mln}$ IU IV during two hours.

- standard scheme: $4400 \mathrm{IU} / \mathrm{kg}$ IV during 10 minutes, then $4400 \mathrm{IU} /$ hour during 12-24 hours.

Dosing during administration to implantable port system:

- rt-PA IV in the dose of $0.9 \mathrm{mg} / \mathrm{kg}$ b.w. (max. $90 \mathrm{mg}$ ):

- $10 \%$ of calculated dose in bolus during 2 minutes;

- remaining $90 \%$ of dose IV during 60 minutes.

\subsection{Contradictions to thrombolytic drugs according to 2014 European Society of Cardiology guidelines [29]}

Absolute contraindications include the following:

- active bleeding to internal organs;

- dissecting aortic aneurysm;

- haemorrhagic stroke;

- cerebrovascular diseases (aneurysms, arteriovenous fistula, vascular malformations);

- tumours of central nervous system;

- ischaemic stroke within last six months;

- head trauma or multiple organ injury or surgery within last three weeks.

- Relative contraindications include the following:

- episode of transient ischaemic attack within last six months;

- bleeding in the gastrointestinal or urinary tract;

- resuscitation procedures leading to organs injury;

- hypertension with values exceeding 200/120 mm Hg;

- severe hepatic insufficiency;

- bacterial endocarditis;

- pregnancy or first week after giving birth;

- active peptic ulcer disease;

- status after biopsy of an organ not susceptible to pressure.

\section{Detailed part}

3. Risk factors, symptoms, forms, and diagnosis of VTE

\subsection{Patient-related risk factors of VTE}

The same as in population of non-cancer patients [23,42]: age $>40$ years (increased risk with age);

- obesity (BMl > $\left.30 \mathrm{~kg} / \mathrm{m}^{2}\right)$;

- positive family history of VTE;

- injuries (especially multiple organs or fracture of the bones of pelvis, proximal part of the femur, and other long bones of lower extremities);

- stroke;

- paresis of lower extremities, long-term immobilisation;

- previous VTE;

- congenital acquired thrombophilia;

- sepsis;

- bedridden patient treated conservatively (e.g. due to severe pneumonia);

- heart failure of III and IV NYHA class;

- respiratory failure;

- autoimmune diseases;

- nephrotic syndrome;

- paroxysmal nocturnal haemoglobinuria;

- pressure on vein (e.g. mass, haematoma, arterial malformation);

- pregnancy and childbed;

- long-term immobility due to advanced cancer, travelling (e.g. flight);

- varicose veins of lower extremities;

- acute infection.

\subsection{Cancer-related risk factors of VTE}

- localization of the cancer (mainly pancreatic, gastric, lung, kidney, ovary cancer, and brain malignant tumours);

- histopathology of cancer (VTE is most common in adenocarcinomas);

- cancer clinical stage;

- increased D-dimer levels exceeding two-fold cut-off value could suggest increased risk of VTE [42]. It should be also underlined that isolated (e.g. with no relation with the clinical presentation) increased D-dimer level is never an indication to initiation of antithrombotic drug administration;

- the highest incidence of VTE is observed within the first 3-6 months after diagnosis of cancer.

\subsection{Treatment-related risk factors of VTE}

- previous surgical operations, including anaesthesia;

- chemotherapy or hormone therapy; 
- antiangiogenic treatment;

- radiotherapy;

- transfusion of red cell concentrates;

- erythropoiesis stimulating agents (ESA);

- corticosteroids;

- central catheters $[3,4,8]$.

\subsubsection{Chemotherapy}

Chemotherapy increases the risk through several mechanisms, including impairment and/or activation of vascular endothelial cells, decreased level of natural coagulation inhibitors, and platelets activation $[3,4,43]$. The results of prospective RCTs showed a significant decrease in VTE incidence in outpatients undergoing chemotherapy, receiving pharmacological antithrombotic prevention, as compare to patients without prevention [44-47]. Patients with pancreatic and lung cancer especially benefit from such prophylaxis $[45,47-56]$. Patients who underwent systemic therapy in clinical settings differed significantly from patients recruited to clinical trials, as they have worse performance status, more advanced age, and more concomitant diseases, thus they are more likely to develop either VTE or bleedings. The type of cancer and its clinical stage, modality of systemic therapy and its duration, combination of systemic therapy with irradiation and supportive care, response to anticancer therapy (e.g. tumour lysis syndrome), patient's nutritional status, hepatic and renal function, patient's mobility, and vascular stasis all definitely influence the risk of VTE in cancer patients.

\subsubsection{Hormone therapy}

Monotherapy with tamoxifen is associated with a 2-3\% risk of VTE, and this risk increases with patient's age; breast cancer postmenopausal women are three-fold more likely to develop VTE than patients before menopause. Aromatase inhibitors are associated with VTE less frequently than tamoxifen; however, the risk of VTE is significantly higher than in the healthy female population who did not undergo such therapy $[3,4]$.

In patients with pancreatic cancer during hormone therapy the risk of DVT and PE significantly increases as compared to such patients without hormone therapy. The risk of VTE is extremely high during therapy with GnRH agonists and oral antiandrogens, and longer hormone therapy duration in men is associated with more frequent VTE $[57,58]$.

\subsubsection{Anti-angiogenic treatment}

The prevalence of VTE is estimated to amount to several to several dozen per cent, depending on which anti-angiogenic drug is used (e.g. bevacizumab, thalidomide, lenalidomide, pomalidomide, gefitinib) [58-65]. The results of meta-analysis indicate the increased relative risk of VTE after treatment with bevacizumab (monoclo- nal antibody against vascular endothelial growth factor [VEGF]) [59]. The general prevalence of VTE in this group of patients is $10.9 \%$ [60]. However, in patients with multiple myeloma the highest prevalence of VTE (34\%) was noted during treatment with thalidomide in combination with doxorubicin, as well as in patients receiving lenalidomide together with high doses of dexamethasone due to recurrent disease [61]. It should be underlined that procoagulant effect of anti-angiogenic treatment increases through combination with cytotoxic drugs or corticosteroids.

Venous thromboembolism risk factors in myeloma patients include:

- patient-related factors: older age, obesity, sedentary lifestyle, immobilisation, past episode of VTE, and genetic predisposition to VTE;

- disease-related factors: renal insufficiency, abnormalities in chromosome 11, increased CRP level, and shortchain disease;

- treatment-related factors: immunomodulatory drugs (thalidomide, lenalidomide, pomalidomide) used alone or in combination with cytotoxic drugs [62].

The majority of VTE episodes in patients with multiple myeloma are diagnosed during the initial treatment period [62].

\subsubsection{Radiotherapy}

Radiotherapy increases the risk of thrombosis through release of procoagulants and cytokines from cancer cells and directly through impairment of vascular vessels, thereby causing activation of vascular endothelial cells, leucocytes, and platelets; this increases also aggregation potential of these latter [63]. Additionally, radiotherapy leads to loss of natural vascular resistance against thrombus formation. Moreover, acute radiation reaction after radiotherapy favours infections, which additionally potentiate procoagulant status.

There is lack of large RTCs, documenting the incidence of VTE in patients who have undergone radiotherapy on different body areas due to a wide range of cancers. However, it was noted that in patients with Hodgkin's lymphoma irradiated on the area of mediastinal lymph nodes and in patients with left breast cancer during adjuvant radiotherapy the risk of cardiovascular complications is 2-7-fold higher as compare to patients without irradiation of that area. The risk of the mentioned complications increases when the radiation dose administered on anterior heart surface exceeds 35-40 Gy [63]. However, it should also be underlined that contemporary treatment of cancer patients is based on combination therapy, and a large proportion of those patients receive radiotherapy in combination with chemotherapy or targeted therapies. For example, radiotherapy in patients with endometrial or cervical cancer is associated with approx. 
$5-7 \%$ risk of VTE, whilst radiotherapy in combination with cisplatin increases the risk of VTE in this group of patients up to $8.5-16.7 \%$ [63]. Venous thromboembolism was also reported after combination therapy (radiotherapy, chemotherapy, and/or targeted therapy) in patients with gastric, oesophageal, head-and-neck cancers as well as malignant brain tumours. Radiotherapy on the chest area in patients with indwelling central venous catheter is an independent risk factor of VTE occurring in upper extremities (OR 7.01; 95\% Cl 1.42-34.66) [literature review in 63].

The patients underwent palliative radiotherapy quite frequently are characterised by limited mobility or even immobilisation, which could be the cause of approx. 15\% of VTE cases. Use of high fractionated doses in patients during palliative radiotherapy could lead to tumour lysis syndrome and releasing procoagulants and cytokines from cancer cells, increasing risk of VTE. Moreover, those patients often enough receive supportive care, which additionally increases the risk of VTE (e.g. cancer-related cachexia treatment - megestrol). In patients undergoing palliative radiotherapy the bleeding risk could be even higher considering the large tumour volume, often infiltrating vascular walls of different calibre blood vessels, as well as the possibility of hypoproteinaemia and hepatic and renal dysfunctions in advanced cancer stages.

\subsection{Symptoms and forms of VTE}

\subsubsection{Lower extremities VTE}

The symptoms of lower extremities VTE could include: increased extremity girth, oedema, erythema, or calf tenderness lower extremity.

\subsubsection{Upper extremities VTE}

Deep venous thrombosis in upper extremities could cause different symptoms, including oedema, erythema, and excessive warmth as well as pain and paraesthesia of upper extremities, pain in shoulder, axilla, lower jaw, head and neck, and visible enlargement of veins in collateral circulation in the area of the shoulder joint and chest. Symptoms of superior vena cava syndrome (SVCS) could be also detected. Difficulties in obtaining blood samples from central catheter or in IV fluids infusion through the catheter suggests thrombosis of the end of the catheter.

\subsubsection{Pulmonary embolism (PE)}

Symptoms of PE are very different and depend on embolism extent and the patient's general condition. The most common symptoms of PE include: tachycardia ( $80 \%$ of patients), tachypnoea, dyspnoea ( $50 \%$ of patients), pleural pain ( $40 \%$ of patients), cough ( $25 \%$ of patients), and more rarely ( $<10 \%$ of patients) the following: increased body temperature, haemoptysis, collapse, or fainting. $80 \%$ of patients with PE also have the symptoms of DVT.

\subsubsection{Migratory thrombophlebitis (Trousseau syndrome)}

It affects only superficial veins, most frequently of atypical location (e.g. veins of upper extremities, chest), and is characterised by spontaneous regressions and recurrences. This entity is not included into the term of VTE, but this is a rare but characteristic syndrome of coagulation disorders in cancer patients. Resistance against antithrombotic treatment is commonly observed.

\subsubsection{Marantic endocarditis}

Physical examination reveals new-onset heart murmurs and symptoms of disseminated embolism in cerebral, coronary, splenic, renal and limbs arteries. Very often the first symptom of this disease is ischemic stroke with no new heart murmurs.

\subsubsection{Hepatic vein thrombosis (Budd-Chiari syndrome)}

The symptoms of this form of VTE include: abdomen discomfort, presence of ascites, hepatomegaly, and abdominal pain.

3.4.7. Thrombosis in the portal vein, splenic vein, mesenteric vein, and the renal veins

These are quite frequent forms of VTE in patients with non-proliferative cancers and in patients with primary hepatic, pancreatic, kidney, and suprarenal cancers. Clinical symptoms include: abdominal pain, splenomegaly, oesophageal varices, and ascites.

\subsubsection{Incidental VTE}

An asymptomatic course of DVT and/or PE is relatively common in cancer patients [63]. Thrombus in pulmonary artery is accidentally detected in approx. 3\% of patients, in which angio-CT is performed due to indications other than suspicion of PE. Cancer patients are considered to be especially exposed to incidental VTE localised in the abdomen [64-68]. It affects $2-5 \%$ of patients in which abdomen $\mathrm{CT}$ is performed.

Symptoms of VDT and PE are not characteristic, and in many cases they raise no concerns among patients as well as clinicians. Deep venous thrombosis symptoms could also be attributable to cancer but not to new pathology $[68,69]$.

It is worth pointing out that VTE is observed in cancer patients regardless of whether the DVT and/or PE episode was symptomatic or asymptomatic [70].

\subsection{Diagnosis}

Diagnosis of VTE in cancer patients differs from the diagnostic rules accepted for remaining patients with VTE [71-75]. In the majority of cancer patients D-dimer levels could be increased without simultaneous VTE. However, a D-dimer level below the cut-off value ("negative D-dimer") does not exclude VTE in cancer patients. 
VTE diagnosis should include US examination of deep veins, which ensures sensitivity and specificity of about 93-100\% related to proximal VTE and over $70 \%$ in the case of the calf VTE using following techniques [34]:

- compression test in B presentation;

- pulse Doppler method;

- colour Doppler sonography;

- duplex Doppler technique.

Palaeography and angio-CT of venous vessels or magnetic resonance angiography (angio-MR) (mainly in suspicions of DVT of iliac veins and thrombosis of superior and inferior vena cava - in borderline cases or proximal DVT of lower extremities) are less frequently performed [23].

Diagnosis of $\mathrm{PE}$ in cancer patients is based on angio-CT of pulmonary arteries, or less frequently on ventilation-perfusion scintigraphy [73].

\section{Guidelines:}

1. In the case of occurrence of PE and/or DVT clinical symptoms, diagnostic tests should be immediately performed - US of deep veins in the case of DVT symptoms and angio-CT of pulmonary arteries in suspicion of PE.

2. In cancer patients with clinical symptoms of DVT and/ or PE antithrombotic treatment should be immediately initiated while waiting for results of diagnostic imaging tests [2C].

\subsection{Searching for cancer in patients with VTE or PE - occult malignancy}

The symptoms of VTE could precede the diagnosis of malignant disease $[76,77]$. In up to $10 \%$ of patients cancer is diagnosed within several to several dozen months (most commonly during the first six months) from idiopathic thrombosis episode - so-called occult malignancy. The most frequent are prostate and colon cancers and more rarely lung, pancreatic, gastric, and bladder cancers [78]. Recently identified risk factors of occult malignancy in patients after first VTE episode include: age > 60 years, current smoking, and previous VTE episode due to transient factor [79].

The SOMIT study indicated that intensive screening diagnosis towards cancer in patients with VTE episode increases the rate of malignant disease diagnosed in early stages, but is not associated with prolonged OS as compare to patients who have undergone routine assessment towards cancer disease [80].

Published in 2015, a Canadian randomised study did not reveal significant differences in the rate of cancer diagnosis in patients with idiopathic VTE, who had undergone standard diagnostic evaluation towards cancers with consideration of gender and age, medical history, morphology and biochemical blood tests, chest X-ray, in women: mammography and cytology exam, and in men: PSA level and prostate palpation, as compared to individuals in which standard evaluation was extended by abdominal and pelvic CT, virtual colonoscopy, and gastroscopy. In the first group, cancers were diagnosed in $3.2 \%$ of patients compared to $4.5 \%$ in the second group [81].

The incidence of cancers is higher in patients with significantly increased $D$-dimer levels during the initial disease phase [82-85], and in patients with bilateral DVT [84] and with early relapse of VTE [86].

\section{Guidelines:}

1. Routine extended diagnostic assessment towards malignant disease in every patient with an episode of idiopathic VTE is not recommended. This procedure could be indicated in elderly patients, with significantly increased D-dimer levels during initial disease phase, and in patients with bilateral DVT and with early relapse of VTE [2C].

2. Detailed physical examination and basic diagnostic tests, including chest X-ray, faecal occult blood test, urological examination in men, and gynaecological examination in women should be performed in every patient with an episode of idiopathic VTE [2C].

3. In patients with VTE and with justified clinical suspicion of malignant disease the diagnosis should be extended towards cancer (CT, endoscopic evaluations, abdominal US, cancer-related markers) [2B].

\section{Prevention of VTE in patients with cancers treated non-surgically \\ 4.1. Prevention of VTE in hospitalised, medically ill cancer patients}

Three large RCTs, including cancer patients (5-15\%), indicated that antithrombotic prevention in acutely ill patients, immobilised in hospital settings, significantly decreased the incidence of VTE as compared to placebo, with low bleeding rates after use of LMWHs or fondaparinux [87-89]. Some cancer patients are hospitalised without any other acute diseases. In those cases, the Padua Prediction Score could be helpful to estimate the risk of VTE (Table II) [90].

There is a lack of unambiguous data from clinical studies regarding the use of routine antithrombotic prevention in patients hospitalised for cancer diagnosis or to administer short-term intravenous infusion of anticancer drugs. In those cases the decision of antithrombotic prevention initiation should be made individually.

\section{Guidelines:}

1. Antithrombotic prevention with LMWHs, UFH (subunit 2.5), or fondaparinux in hospitalised, medically ill cancer patients is recommended [1 $\mathrm{A}$ ].

2. In hospitalised, medically ill cancer patients with previous VTE episodes, or in those immobilised or with venous blood flow from a lower body part blocked by a growing tumour, antithrombotic prevention 
Table II. Assessment of risk factors of venous thromboembolism (VTE) in hospitalised patients — Padua Prediction Score [90]

\begin{tabular}{|c|c|}
\hline Risk factors & Score \\
\hline $\begin{array}{l}\text { Active malignant disease (patients with metastases to regional lymph nodes or with distant metastases, undergoing chemotherapy or } \\
\text { radiotherapy during the last } 6 \text { months) }\end{array}$ & 3 \\
\hline Past VTE (except thrombosis of superficial veins) & 3 \\
\hline $\begin{array}{l}\text { Immobility (assumed need for staying in bed [with possibility of using bathroom/toilet] due to patient's disability or physician order } \\
\text { for } \geq 3 \text { days) }\end{array}$ & 3 \\
\hline $\begin{array}{l}\text { Diagnosed thrombophilia (antithrombin, protein C or S deficiency, mutation of factor V Leiden, mutation G20210A } \\
\text { in prothrombin gene or antiphospholipid syndrome) }\end{array}$ & 3 \\
\hline Recently past ( $\leq 1$ month) injury or surgery & 2 \\
\hline Age $\geq 70$ years & 1 \\
\hline Heart or respiratory failure & 1 \\
\hline Recent myocardial infarction or ischaemic stroke & 1 \\
\hline Acute infection or rheumatic disease & 1 \\
\hline Obesity (BMI $\geq 30$ kg/m²) & 1 \\
\hline Hormone therapy & 1 \\
\hline $\begin{array}{l}\text { Total result } \geq 4 \text { points indicates high risk of VTE } \\
\text { Total result }<4 \text { points indicates low risk of VTE }\end{array}$ & \\
\hline
\end{tabular}

VTE - venous thromboembolism; BMI — body mass index

with LMWHs, UFH, or fondaparinux (subunit 2.5) is recommended, provided there are no contraindications to pharmacological antithrombotic prevention or high risk of haemorrhagic complications (subunit 2.6) [1C].

3. In hospitalised cancer patients with increased risk ofVTE, use of mechanical antithrombotic prevention should be considered (PUP and PESU — subunit 2.7) [2C].

4. Routine antithrombotic prevention is not recommended in cancer patients hospitalised for diagnostic evaluation or for administration of short-term intravenous infusion of cytotoxic drugs [2C].

5. Pharmacological antithrombotic prevention is not recommended in cancer patients with current bleeding or with high risk of bleeding (subunit 2.6). In those cases, mechanical antithrombotic prevention (PUP and PESU - subunit 2.7) is recommended.

6. It is recommended not to use acetylsalicylic acid (ASA) as a single method of antithrombotic prevention during hospitalisation $[2 \mathrm{C}]$.

\subsection{Prevention of VTE in outpatients undergoing non-surgical anticancer treatment}

Prevention of VTE should be introduced only in patients with increased risk of that disorder. For this reason, the scale of VTE risk assessment in cancer patients receiving chemotherapy in outpatient settings (the so-called Khorana Risk Score) was developed and validated (in the PROTECHT and SAVE-ONCO studies) (Table III) [91-93]. According to this score, patients are divided into three groups, e.g. with low (0 points), moderate (1-2 points), and high (more than 3 points) risk of VTE induced by chemotherapy (Table II). VTE risk in particular groups accounts for $0.3 \%, 2 \%$, and $6.7 \%$,
Table III. Khorana Risk Score (with ASCO modification) of venous thromboembolism risk in outpatients undergoing chemotherapy $[8,91]$

\begin{tabular}{ll}
\hline Risk factors & Score \\
\hline Target organ and histological type & 2 \\
Very high risk & \\
- gastric adenocarcinoma & \\
- pancreatic adenocarcinoma & \\
- malignant brain tumours & 1 \\
High risk & \\
- lung cancer & \\
- lymphomas & \\
- gynaecological cancers & \\
- bladder cancer & \\
- testicular cancer & \\
- kidney cancer & \\
Haematological risk factors & 1 \\
- platelets count before chemotherapy $\geq 350 \mathrm{G} / \mathrm{l}$ & 1 \\
- haemoglobin level < $10 \mathrm{~g} / \mathrm{dl}$ or ESA using & 1 \\
- leucocyte count before chemotherapy > $11 \mathrm{G} / \mathrm{L}$ & 1 \\
Patient-related factors & \\
- BMl $\geq 35 \mathrm{~kg} / \mathrm{m}^{2}$ & \\
\hline ESA - erythropoiesis stimulating agents; BMI - body mass index & \\
\hline & \\
\hline
\end{tabular}

respectively. This predictive model allows identification of the patients with high risk of VTE [2B]. The Khorana Risk Score (Table III) does not include poor general patient state and some types of cancers connected to high risk of VTE, for example brain tumours.

The Khorana Risk Score of VTE risk in cancer patients undergoing chemotherapy was modified by Ay et al. [94]. They added serum P-selectin and D-dimer levels to five parameters covered by the original model. The probability of symptomatic or fatal VTE is then $35 \%$ in patients with $\geq 5$ risk factors, $10.3 \%$ with 3 risk factors, and $1.0 \%$ with no risk 
factors. The limitation of the modified score is that P-selectin is not routinely assessed in clinical practice and there are no tests registered for clinical use.

To date there is no strong evidence justifying routine antithrombotic prevention in patients undergoing radical radiotherapy or radiochemotherapy or palliative radiotherapy.

\section{Guidelines:}

1. Routine antithrombotic prevention in cancer patients undergoing chemotherapy in outpatient settings is not recommended [2C].

2. Antithrombotic prevention could be considered in patients undergoing chemotherapy in outpatient settings with high risk of VTE, e.g. in patients with advanced pancreatic cancer [1B] or non-small cell lung cancer (NSCLC), provided that they have low risk of bleeding and no contraindications to anticoagulants [2B].

3. Every patient with multiple myeloma should be assessed for VTE risk (subunit 3.1) and receive appropriate antithrombotic prevention [1 A]

4. Patients with multiple myeloma are recommended to receive the following VTE prevention [62]:

a. $\leq 1 \mathrm{VTE}$ risk factor: ASA in the dose of $100 \mathrm{mg} / \mathrm{d}$ [1B];

b. $\geq 2$ VTE risk factors: LMWHs in prophylactic dose or VKA with target INR value between 2.0-3.0 [1B];

c. LMWH should be administered for at least four months and then could be replaced by ASA [2C].

5. In the remaining patients undergoing chemotherapy in outpatient settings the decision of antithrombotic prevention initiation should be made individually, based on analysis ofVTE risk (subunit 3.1) and individual assessment of benefits and possible complications of such prevention.

6. It is recommended that ASA is not used as the single method of antithrombotic prevention [2C].

7. In cancer patients undergoing chemotherapy in outpatient settings with increased risk of VTE use of PUP and PESU should be considered (subunit 2.7).

8. Routine antithrombotic prevention in patients undergoing radical radiotherapy, radiochemotherapy, or palliative radiotherapy is not recommended.

9. In patients during radical radiotherapy, radiochemotherapy, or palliative radiotherapy the decision of antithrombotic prevention initiation should be made individually with consideration of VTE risk factors, associated with general patient's state, concomitant diseases, cancer type and stage, and combination of radiotherapy with systemic treatment.

\subsection{Antithrombotic prevention in patients with indwelling central venous catheter}

Clinically overt subclavian artery thrombosis occurs in approx. $5 \%$ of patients; however, incidental for of that disor- der is diagnosed in up to $14-18 \%$ of patients with indwelling central venous catheters [95]. There is no evidence of $L M W H$ or VKA efficacy in VTE prevention in patients with indwelling central venous catheters [96].

\section{Guidelines:}

1. Routine antithrombotic prevention in cancer patients with indwelling central venous catheters is not recommended $[2 \mathrm{C}]$.

2. Catheters should be inserted on right body side; however, the catheter's end should be placed close to the superior vena cava-right atrium junction in order to decrease the risk of thromboembolic complications [2C].

3. Antithrombotic prevention in patients with high VTE risk should be individualised [2C].

\subsection{Prevention of VTE in patients with concomitant thrombocytopaenia}

Guidelines of antithrombotic prevention use in patients with thrombocytopaenia are based on data from observational studies, conducted in relatively small groups of patients treated in single centres [97-103]. In this group of patients mechanical VTE prevention methods could be used, except for pharmacological antithrombotic prevention.

\section{Guidelines:}

1. In acutely ill patients with active cancer, hospitalised due to non-surgical disease, pharmacological VTE prevention is recommended in standard doses, provided that platelet count is $\geq 50 \mathrm{G} / \mathrm{l}$ and there are no symptoms of haemorrhagic diathesis and no additional haemostasis disorders [2C].

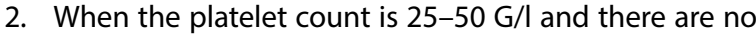
symptoms of haemorrhagic diathesis the decision of using anticoagulants in standard doses or their decrease or abandonment of antithrombotic prevention should be based on analysis of potential benefits and risk resulted from the therapy $[2 \mathrm{C}]$.

3. In patients with platelet count $<25 \mathrm{G} / \mathrm{l}$ it is suggested not to use antithrombotic prevention, and in this case mechanical antithrombotic prevention methods (PUP and PESU - subunit 2.7) could be used [2C].

4. When thrombocytopaenia is accompanied by active haemorrhagic diathesis and/or concomitant haemostasis disorders it is suggested not to use pharmacological antithrombotic prevention. In this case mechanical VTE prevention methods are recommended (PUP and PESU — subunit 2.7).

5. The above recommendations relate also to cancer patients with concomitant thrombocytopaenia, who needed antithrombotic prevention for reasons other than hospitalisation due to acute non-surgical disease, e.g. outpatients. 


\subsection{Antithrombotic prevention in patients with concomitant renal insufficiency}

During chronic renal disease with declined eGFR not only pharmacokinetics of anticoagulant drugs excreted by the kidney (LMWHs, fondaparinux, DOAC), but also plasma protein binding and distribution volume are changed. The risk of bleeding complications in patients with impaired renal function during use of anticoagulants is increased due to decreased clearance of the drugs and their prolonged activity. Other factors increasing the risk of bleedings include: older age, obesity, and concomitant use of antiplatelet drugs. There is a lack of large, prospective RCTs assessing the efficacy and safety of anticoagulant drugs in this group of patients. Thus, the potential benefits and bleeding risk during use of anticoagulants in patients with impaired renal functions should always be assessed individually.

\section{Guidelines [23, 104, 105]:}

1. In patients with impaired renal function (eGFR $<30 \mathrm{ml} /$ min) UFH in the dose of 5000 IU s.c. every eight hours is preferred because elimination half-life of LMWHs and fondaparinux is prolonged in renal insufficiency, and those drugs could be accumulated in plasma [2C].

a. When long-term administration of LMWHs is indicated in patients with impaired renal function the measurement of anti-Xa activity during dose establishment in serum from blood sample obtained four hours after LMWH injection could be helpful to decrease bleeding risk. Target value of anti-Xa should not exceed $0.5 \mathrm{IU} / \mathrm{ml}$;

b. Administration of LMWH in doses reduced by half is an alternative.

2. In patients with high risk of bleeding, who need antithrombotic prevention, mechanical preventive methods (PUP and/or PESU) are recommended.

\subsection{Antithrombotic prevention in terminally ill cancer patients treated in hospices}

Patients in advanced cancer stage treated in hospices are classified into the group of high VTE/PE risk, among others due to older age, advanced loco-regional disease (vascular stasis caused by external pressure of large tumour mass leads to blood flow disturbance and favours VTE), or massive distant metastases as well as reduced patient mobility [106]. Clinically overt PE develops in approx. $10 \%$ of hospice patients [106]. Additionally, it is estimated that half of stationary hospice patients report clinically asymptomatic DVT $[107,108]$. Those patients receive different drugs, which could additionally increase the risk of VTE, e.g. megestrol, commonly used in cancer patients with cachexia, associated with $30 \%$ risk of complications, mainly DVT of lower extremities. The main benefit of antithrombotic prevention in patients treated in hospices, where the best possible quality of life is a priority but not obstinate life prolongation, could be reducing the risk of VTE symptoms occurrence, including pain, oedema, or dyspnoea [106]. However, there is a lack of clinical studies conducted in the patient groups with appropriate sample sizes, which could unambiguously assess the influence of antithrombotic prevention on VTE symptoms or survival of hospice the patients [109].

Antithrombotic prevention in cancer patients treated in hospices is a challenge for many reasons: unknown influence of quality of life, unclear risk of VTE after cessation of antithrombotic prevention, bleeding risk, additionally increased in malnourished patients and in patients with reduced eGFR, interactions of many drugs with VKA, and direct and indirect costs of that management [110-113].

\section{Guidelines:}

1. Routine antithrombotic prevention in all cancer patients treated in hospices is not recommended [2C].

2. In every patient the decision about antithrombotic prevention initiation should be made individually, considering VTE risk, co-morbidities, and bleeding risk [2C].

\subsection{Prevention of VTE in pregnant women diagnosed with cancer}

Indications to VTE prevention in pregnant women with cancer are the same as in other cancer patients. Pregnancy increases the risk of VTE occurrence; however, other concomitant VTE risk factors in pregnant women with cancer justify initiation of antithrombotic prevention. Similarly to general antithrombotic prevention in cancer patients, LMWHs and UFH are preferred in pregnant women because those anticoagulants do not cross the placenta, unlike VKA. VKAs are contraindicated during the first three months of pregnancy (due to teratogenic effect), but also during second and third trimester they are reluctantly used as they increase risk of bleeding in the mother and especially in the foetus. DOACs are contraindicated during pregnancy [114]. Fondaparinux is not indicated during pregnancy, but there are single reports indicating its safety and efficacy in VTE prevention in pregnant women, e.g. in the case of HITT occurrence.

Elective caesarean section is very rarely complicated by VTE, so routine antithrombotic prevention is indicated when there are additional risk factors (e.g. cancer) $[115,116]$.

\section{Guidelines:}

1. Indications to VTE prevention in pregnant women with cancer are the same as in other cancer patients.

2. LMWHs and UFH are the preferred anticoagulants in antithrombotic prevention in pregnant women with cancer $[2 \mathrm{C}]$.

3. Dosing of LMWHs and UFH in pregnant women with cancer is the same as in other cancer patients. However, 
in the case of additional risk factors, e.g. obesity, previous VTE episode, or concomitant congenital thrombophilia/antiphospholipid syndrome, higher LMWH doses (even therapeutic) could be recognised, based on anti-Xa activity when necessary [2C].

4. In pregnant women with cancer undergoing caesarean section, pharmacological antithrombotic prevention in standard doses should be used [2C].

5. After occurrence of active haemorrhagic diathesis, deep thrombocytopaenia, or other haemostasis disturbances, increasing the bleeding risk in pregnant women with cancer and high VTE risk mechanical preventive methods (PUP, PESU — subunit 2.7) should be considered.

\section{Treatment of cancer patients with VTE}

The aim ofVTE treatment in cancer patients is prevention of acute and chronic complications. Cancer patients have a 2-5-fold increased risk of VTE recurrence and 2-6-fold increased risk of major bleedings as compare to the population of patients with VTE but without cancer [1-4]. Every time, the bleeding risk (subunit 2.6) and potential benefits from antithrombotic treatment should be balanced $[13,108]$.

Very often, fast appropriate diagnosis of PE and initiation of adequate treatment are of extreme importance for the further life of patients with PE complicating the clinical course of cancer [13, 24, 109-111]. The majority of $\mathrm{PE}$ cases are embolisms that do not require thrombolytic treatment. The treatment of patients with PE is based on procedures aiming at restoration of pulmonary vasculature patency, reduction of VTE recurrence risk, and maintaining appropriate perfusion and oxygen delivery to important organs and systems, despite haemodynamic and respiratory disturbances caused by PE. There are two main periods of PE treatment: initial and long, chronic antithrombotic treatment, continued for many months.

\subsection{Initial treatment of cancer patients with VTE or PE with no need for thrombolytic therapy}

The efficacy of LMWHs during initial VTE treatment was comparable to UFH, with lower risk of bleeding complications [117-123]. It was observed in Cochrane analysis including cancer patients that the efficacies of LMWHs, UFH, and fondaparinux during initial VTE treatment were comparable [124].

During initial treatment of cancer patients with concomitant VTE not requiring thrombolytic therapy therapeutic doses of heparins (LMWHs, UFH) or fondaparinux are used. LMWHs are the most frequently used drugs during PE treatment in cancer patients, but only in patients with high risk PE therapy starts with infusion of UFH followed by thrombolytic treatment [75, 125-133].

The percentage of cancer patients in RCTs regarding efficacy and safety of DOAC during initial treatment of VTE was low $(<10 \%)$, so those drugs should not be used in this phase of therapy in cancer patients with concomitant VTE. Unfractionated heparin is still the backbone drug in patients with clinically justified suspicious or confirmed diagnosis of VTE. It should be used in optimal doses because it was shown that inadequate APTT prolongation (or insufficient increasing of anti-Xa activity) within the first 24 hours of treatment could increase VTE risk by even more than ten times [40]. On the other hand, it was also proven that administration of UFH in continuous infusion in total daily dose exceeding 30,000 or 35,000 IU protects the patient against recurrence of VTE, regardless of APTT value. Fondaparinux is another drug used during the initial phase of VTE treatment. The MATISSE PE study [133] indicated that fondaparinux is safe and efficacious in patients with $\mathrm{PE}$, similarly to UFH.

Abandonment of antithrombotic treatment (for many reasons, e.g. high bleeding risk) or overlooking the thrombus in angio-CT scans in patients with incidental VTE led to increased mortality [134].

ACCP guidelines recommend using of antithrombotic treatment in cancer patients with accidental diagnosis of DVT or PE [135].

\section{Guidelines:}

1. Treatment of DVT or PE in cancer patients is similar to that used in non-cancer patients.

2. Cancer patients with concomitant DVT or PE, who do not require thrombolytic treatment, could be treated in outpatient settings, provided that the following conditions are fulfilled [39]: stable clinical patient's state, adequate basic vital signs, low bleeding risk, serum creatinine concentration below $150 \mu \mathrm{mol} / \mathrm{l}$ or eGFR over $60 \mathrm{ml} / \mathrm{min}$, ensured system of antithrombotic drugs administration and professional supervision by trained nurse or physician towards bleeding complications, efficacy of antithrombotic treatment, and recurrence of VTE.

3. Cancer patients with concomitant extensive, proximal DVT, or PE requiring either antithrombotic therapy or embolectomy should be treated in hospital settings.

4. Every time, bleeding risk and potential benefits of antithrombotic treatment should be balanced.

5. LMWHs given s.c. are recommended during initial treatment in the majority of cancer patients diagnosed with VTE (subunit 2.5.1) [1B].

6. During LMWH treatment, moderate patient activity is recommended $[2 \mathrm{C}]$.

7. Patients with VTE are recommended to be mobilised with simultaneous using of pressure therapy (PUP, PESU - subunit 2.7), provided that there are no contraindications. Periodic control of local state and tolerability of pressure therapy is also recommended [2C]. 
8. In cancer patients with contraindications to LMWHs treatment with UFH (IV or s.c.) (subunit 2.5.2) or fondaparinux (subunit 2.5.3) is recommended [2C].

9. DOAC are not recommended during initial treatment of cancer patients with concomitant VTE $[2 \mathrm{C}]$.

10. Thrombolytic treatment (subunit 2.8) in cancer patients with concomitant DVT should be considered only in cases with massive limb-threatening changes in iliofemoral vessels. Good prognosis (expected survival time at least one year), low bleeding risk, and no contraindications to thrombolytic treatment are necessary conditions. Described management should be initiated no later than 14 days after onset of clinical symptoms [2C]. In the abovementioned case the drugs should be administered during 1-2 days in very low doses through a catheter inserted inside the thrombus. Systemic thrombolytic treatment could be used in specific situations, among others when the thrombolytic drug cannot be delivered inside the thrombus due to lack of an experienced treating team.

11. In patients with incidental VTE the management should be the same as during symptomatic VTE $[2 \mathrm{C}]$.

\subsection{Initial treatment of cancer patients with PE with need for thrombolytic therapy}

UFH IV is recommended during initial treatment of this group of patients. In justified cases LMWHs could be considered. There are very few reports of using LMWHs in patients with $\mathrm{PE}$ requiring thrombolytic treatment but their results are quite encouraging.

In patients with shock induced by PE thrombolytic treatment should be introduced. However if it fails or could not be used, surgical embolectomy should be considered or transdermal treatment through catheter. Thrombolytic drugs should be used in patients with PE and concomitant shock or severe hypotension (preshock state is defined as decline of systolic blood pressure by $40 \mathrm{~mm} \mathrm{Hg}$ during 15 minutes). In patients with cardiac arrest thrombolytic drugs could be difficult to administer. However, if a patient with cardiac arrest is in intensive care room and potential cause of this state could be PE, thrombolytic treatment during cardiopulmonary resuscitation could be possible. In patients with PE thrombolytic drugs should be administered to peripheral veins. It was not shown that administration of thrombolytic drugs directly to pulmonary artery improves outcomes.

Pulmonary embolectomy with extracorporeal circulation in normo- or hypothermia is the basic surgical method of treatment of acute $\mathrm{PE}$, with death risk of $6 \%$ in experienced medical centers. It allows detailed assessment and removal of thrombotic tissue from the right ventricle, right atrium, as well as the pulmonary artery $[136,137]$.
In the subgroup of patients with absolute contraindications to anticoagulation or after PE recurrence despite thrombolytic treatment, venous filters should be considered, which protect pulmonary circulation against in-flowing thrombi from deep veins of lower and upper extremities. Filters also reduce PE risk and subsequently cardiac arrest risk and death, but could additionally increase the risk of post-thrombotic syndrome (PTS) $[137,138]$.

In all patients with $P E$ requiring thrombolytic treatment, adequate supportive care is needed.

\section{Guidelines:}

1. Initial treatment of cancer patients with concomitant PE requiring thrombolytic treatment or embolectomy should be conducted in hospital settings [1C].

2. In patients with planned thrombolytic treatment UFH should be used as initial treatment (subunit 2.5 and 5.1) $[1 \mathrm{C}]$

3. In treatment of cancer patients with PE during the first month of therapy and after stabilisation of patient's state LMWHs are recommended and administered in therapeutic doses in two injections daily, which reduces the bleeding complication rate compared to administration of those drugs once daily only (subunit 2.5.1).

4. In cancer patients with concomitant high-risk PE, thrombolytic drugs are recommended (subunit 2.8), provided that there are no contraindications.

5. Thrombolytic drugs are recommended to be administered to peripheral veins but not to the pulmonary artery.

6. When recombinant tissue plasminogen activators (rtPAs) cannot be used in patients with PE and shock or hypotension, streptokinase should be introduced (subunit 2.8). After cessation of thrombolytic treatment, UFH infusion should be initiated with an initial rate of 1000 $\mathrm{IU} /$ hour, continuing antithrombotic therapy according to general rules (subunit 2.5.2)

7. Recurrence of PE requiring thrombolytic treatment in patients with previous SK treatment (between four days and nine months) is an indication to rt-PA (subunit 2.8).

8. In patients with cardiac arrest, possibly as a result of $P E$ requiring thrombolytic treatment, a rt-PA bolus should be used (subunit 2.8). The advantage of an rt-PA bolus over two hours of SK therapy is based on possibly faster reduction of pulmonary resistance after rt-PA.

9. 12-hour administration of thrombolytic drugs in cancer patients with concomitant $\mathrm{PE}$ is not recommended because such long treatment duration is associated with unacceptable increase in bleeding rate in this group of patients.

10. In patients with shock resulting from $P E$ requiring thrombolytic treatment after failure of thrombolytic drugs, pulmonary embolectomy should be considered. 
11. Indications to pulmonary embolectomy are as follows:

a. shock and massive obturation of pulmonary artery in patients with contraindications to thrombolytic treatment (early period after surgical procedure or intra-operative embolism);

b. failure of thrombolytic treatment [21, 23].

12. In some cancer patients with concomitant PE, implantation of inferior vena cava filter should be considered.

13. Indications to implantation of inferior vena cava filter are as follows:

a. initiating or continuation of PE causative treatment is impossible due to contraindications or treatment complications;

b. PE treatment according general rules failed, with signs of $\mathrm{PE}$ recurrence;

c. status after embolectomy or planned thromboendarterectomy without any contraindications to anticoagulation.

14. Specific indications to implantation of retrievable inferior vena cava filter associated with PE risk could be considered in exceptional cases. It relates to patients with absolute contraindications to pharmacological thrombolytic treatment, occurrence of complications after thrombolytic treatment, or failure of adequately conducted thrombolytic treatment [23].

15. In all patients, adequate supportive therapy is necessary, which very often has extreme importance for the patient's further life:

a. all patients with PE and with shock, significant decline of blood pressure, respiratory failure, significant overloading of right ventricle, or cardiac arrhythmia need to be treated in intensive supervision units;

b. in case of shock, invasive blood pressure monitoring (haemodynamic line) is essential;

c. patients with acute respiratory distress should have adequate oxygen supply - in most cases nasal canola or mask precisely maintaining specific oxygen concentration in gas mixture is sufficient;

d. in case of advanced, acute disorders, therapy with techniques of non-invasive ventilation should be initiated, and in exceptional cases intubation and mechanical ventilation is indicated;

e. in patients with hypotension or shock, catecholamines should be administered. The treatment should be initiated with dopamine, and if it fails noradrenalin and dobutamine are used.

\subsection{Long-term and chronic treatment of cancer patients with VTE}

RCTS (LITE, CLOT, ONCENOX, CANTHANOX) and meta-analyses indicate that LMWHs used in long-term treatment is associated with approx. 50\% reduction of VTE recurrence rate as compared to VKA administration with similar bleeding risk [46, 118-124, 135]. The CLOT study was a breakthrough clinical trial, assessing the efficacy and safety of LMWHs in VTE treatment in cancer patients [123]. Cancer patients suffering from DVT and/or PE received dalteparin in the dose of $200 \mathrm{lU} / \mathrm{kg} \mathrm{b.w.} \mathrm{once} \mathrm{daily}$ for 5-7 days and VKA (to maintain INR between 2.0-3.0) or dalteparin in the dose of $200 \mathrm{IU} / \mathrm{kg}$ b.w. once daily during the first month, and then $150 \mathrm{lU} / \mathrm{kg}$ b.w. once daily during next five months. The probability of VTE recurrence during six months of follow-up was $17 \%$ in the group receiving VKA and $9 \%$ in patients with long-term treatment with dalteparin [hazard ratio (HR) $0.48, \mathrm{P}=0.002$ ]. There were no differences in major bleeding rates and mortality between both groups. Two other studies [121, 122] confirmed efficacy of enoxaparin and tinzaparin in the chronic treatment of VTE in cancer patients as compares to initial therapy with LMWHs followed by VKA. Systematic review and Cochrane analysis comparing efficacy of LMWHs and VKA in longterm treatment showed decreased VTE recurrence rate after LMWHs compared to patients receiving VKA (RR 0.49; $95 \% \mathrm{Cl} 0.34-0.70$ ) with similar bleeding rate [46]. Additionally, it was indicated that use of only full or medium but not prophylactic dose of LMWH shows advantages over VKA administration in prevention of VTE recurrences [121]. Furthermore, RTCs and meta-analyses showed the advantages of LMWHs over VKA in chronic treatment (up to six months) [46, 118-120].

Based on results of the LITE, CLOT, ONCENOX, and CANTHANOX studies on VTE treatment in cancer patients, it was noted that initial therapy with therapeutic doses of LMWHs should be prolonged up to at least one month, and then reduction of LMWH dose to $75-80 \%$ of baseline therapeutic dose should be consider or full doses of $\mathrm{LMWH}$ should be continued at least during the first three months of treatment [118-123].

Optimal duration of LMWHs treatment in cancer patients who experience DVT is still debatable. Continuation of antithrombotic treatment beyond 3-6 months and the means of its administration should be taken individually, considering the risk of VTE recurrence and possible complications. The DALTECAN study, including 334 cancer patients with concomitant VTE, indicated that use of dalteparin for the first month in the dose of $200 \mathrm{IU} / \mathrm{kg}$ body weight (no more than 18,000 IU) and then its continuation for 2 to 12 months in the dose of 7,500 IU in patients with body weight not higher than $56 \mathrm{~kg}, 10,000 \mathrm{IU}$ in patients with body weight between $56-68 \mathrm{~kg}, 15,000 \mathrm{IU}$ in patients with body weight between 83-98 kg, and 18,000 IU in patients with body weight over $99 \mathrm{~kg}$, was associated with low bleeding rate (10.2\% of patients), but the highest bleeding risk was observed during the first month of antithrombotic treatment [139]. VTE recurrences were reported in $11.1 \%$ of patients (5.7\% during the first month, $1.34 \%$ during 2-6 months, 
and $4.1 \%$ during 7-12 months). However, analysis of data from the RIETE database indicated that among 7,911 cancer patients (in active stage) undergoing antithrombotic treatment for a mean period 181 days ( \pm 210 days) PE recurrences were observed in 178 patients and DVT recurrences in 194 patients, whilst in 367 patients bleedings were reported. Among 4,125 patients with PE 45 patients died from PE recurrence, and 45 from bleeding. However, among 3,786 patients with previous DVT -19 patients died from $\mathrm{PE}$, and 55 patients dies due to bleeding [13].

Risk of VTE recurrence can be assessed according to the Louzada score (Table IV) [140].

Prolongation of LMWHs administration beyond six months in the treatment of first VTE episode in cancer patients should be considered in patients with stage IV malignant brain tumours, lung, ovarian, gastrointestinal cancer, with metastases to bone marrow and dysplasia of bone marrow, or with paresis of extremities and stage III neurological syndromes [141].

The beneficial influence of LMWHs on decreasing VTE recurrence rate is observed only during their administration and does not transfer to the period after cessation of antithrombotic treatment [142]. The duration of chronic treatment depends on the presence of VTE risk factors and should last as long as they maintain. In some patients there is a consistently increased risk of VTE recurrence, suggesting some benefits from indefinite antithrombotic treatment, e.g. in the case of active cancer. In patients with transient risk factor (e.g. immobilisation) the risk of VTE recurrence decreases with time.

LMWHs and UFH are used in the treatment of cancer patients with VTE [24]. Administration of ASA is suggested after cessation of antithrombotic treatment, but there are very few data regarding such management in cancer patients [143, 144].

DOAC showed similar efficacy in VTE treatment as compared to standard therapy with heparin and then warfarin, as well as similar bleeding risk in subanalyses of large clinical studies with those drugs in VTE treatment [145]. However, these observations are based on studies with small sample sizes (cancer patients accounted for $5 \%$ of the total group on average, and they were even excluded from some studies). There was no significant advantage of one DOAC drug over another in comparative analyses of cancer patients. There are also available data suggesting lower VTE recurrence risk in cancer patients receiving DOAC in acute disease phase, as compare to standard treatment, most likely in connection with better stability of anticoagulation compared to warfarin, resulting from lack of diet influence and rare drug-drug interactions [146]. Malignant disease with high bleeding risk is a contraindication to DOAC treatment. Thus, based on observational studies DOAC could be a therapeutic option in cancer patients treated for VTE when other drugs, espe-
Table IV. The Louzada score for assessment of the risk of venous thromboembolism recurrence in cancer patients [140]

\begin{tabular}{ll}
\hline Risk factor & Score \\
\hline Female gender & 1 \\
Lung cancer & 1 \\
Breast cancer & -1 \\
TNM, CS I & -2 \\
Previous VTE & 1 \\
Score: $\leq$ 0 - low recurrence risk; $\geq \mathbf{1}$ - high recurrence risk \\
\hline TNM - classification of cancer clinical stage (T - tumour, N - lymph node, M \\
- metastases); CSI - clinical stage I
\end{tabular}

cially heparin, are not tolerated or are ineffective, or due to patient's preferences, e.g. in patients with hypersensitivity to LMWHs or after HITT episode. Use of DOAC in cancer patients is discouraged, especially in elderly patients, having higher bleeding risk. Major bleeding risk, mainly from the gastrointestinal tract, is a relative contraindication to DOAC because those drugs are active in the gastrointestinal tract, which increases the risk of the complication as compared to other anticoagulants. Anticancer drugs metabolised through 3A4 cytochrome or transported by P-glycoprotein [bortezomib, cyclosporine, dexamethasone, most of tyrosine kinase inhibitors (TKIs), tamoxifen, some immunomodulatory drugs, supportive drugs (e.g. fentanyl, methadone, clonazepam, ondansetron, aprepitant, and fosaprepitant)] intensify anticoagulation effects of DOAC and increase bleeding risk. Thereby, in this group of patients, measurement of blood drug concentrations could be very useful [147]. In Europe dabigatran is not recommended in patients treated with cyclosporine or tacrolimus - potent inhibitors of P-glycoprotein. Patients with eGFR below $30 \mathrm{ml} / \mathrm{min}$ or worsening kidney functions should not be treated with DOAC to decrease major bleeding risk. eGFR monitoring 2-3 times yearly improves the safety of DOAC treatment. Periodical monitoring of liver function and complete blood count including platelet count is also recommended in patients treated with DOAC.

To date, treatment with DOAC was not assessed in RCTs in cancer patients suffering from VTE [148-151].

\section{Guidelines:}

1. LMWHs are preferred in long-term and chronic treatment of cancer patients with VTE over VKA [1 A] or DOAC $[2 \mathrm{C}]$.

2. Considering high VTE recurrence risk, initial therapy with therapeutic doses of LMWHs (subunit 2.5.1) in cancer patients with VTE should be prolonged up to at least one month, and then reduction of $\mathrm{LMWH}$ dose to $75-80 \%$ of baseline therapeutic dose should be considered or full doses of LMWH should be continued at least during the first three months of treatment (long-term treatment) $[1 \mathrm{~A}]$. 
3. DOAC should not be used in VTE treatment in cancer patients, unless other drugs cannot be used or they are insufficient or this decision is based on the patient's preferences.

4. Long-term antithrombotic therapy is recommended in cancer patients after PE. After one month of initial treatment chronic LMWH therapy should be continued for the next five months, with use of $75-80 \%$ of therapeutic dose (subunit 2.5.1).

5. Beyond six months after past $P E$, treatment with $L M W H$ could be continued if still indicated.

6. Drugs from the VKA group could be used as needed after six months of LMWH administration. Target INR values should be in the range between 2.0-3.0 (subunit 2.5.4).

7. In patients with PE complicated by chronic pulmonary hypertension, chronic treatment should be administered for an indefinite period.

8. When there is no possibility to use, or there are contraindications to, long-term administration of LMWH in cancer patients VKA therapy is suggested as an alternative management (subunit 2.5.4) [1B].

9. In patients with active cancers, LMWHs or VKA could be chronically used, if not contraindicated, with periodical assessment towards the need to continue antithrombotic therapy (at least one per year) [2C].

10. Antithrombotic drugs should be administered until the patient's recovery from cancer or until the end of life when the cancer is not curable.

11. In patients with symptomatic thrombosis of mesenteric or hepatic veins antithrombotic treatment should be used, but in case of accidental diagnosis it is suggested not to initiate a therapy.

12. Cancer infiltration of the pericardium requires that antithrombotic treatment be conducted with caution.

13. In patients with primary brain malignant tumours and concomitant VTE, antithrombotic treatment is recommended as in cancer of other localizations, but the patient should be monitored more frequently in order to avoid bleeding complications.

14. When paracentesis or other surgical procedures are planned in cancer patients treated with VKA, oral antithrombotic treatment should be interrupted and instead LMWHs should be used.

15. When VTE is diagnosed during anticancer non-surgical treatment, chemotherapy and/or radiotherapy should be continued with concomitant administration of appropriate antithrombotic treatment in adequate doses, unless there are any special conditions.

16. In cancer patients with concomitant VTE requiring surgical operation the best decision would be to postpone the procedure by up to three months, but if impossible, implantation of a retrievable inferior vena cava filter could be considered, if VTE is presented as proximal DVT of lower extremities.

17. In breast cancer patients treated with tamoxifen with concomitant VTE it is recommended to replace this drug with an aromatase inhibitor, and then after administration of LMWHs in full doses, continuation of treatment with $75-80 \%$ of baseline doses should be considered (subunit 2.5.1).

18. In cancer patients with concomitant VTE during adjuvant chemotherapy after administration of LMWHs in full doses, continuation of treatment with $75-80 \%$ of baseline doses for the next six months should be considered (subunit 2.5.1).

19. In cancer patients with $C R$ after systemic curative treatment and with concomitant VTE during chemotherapy, after administration of LMWHs in full therapeutic doses, continuation of treatment with $75-80 \%$ of baseline doses for the next six months should be considered (subunit 2.5.1).

20. In cancer patients during palliative chemotherapy achieving $C R$, even in patients with high cancer recurrence risk, the duration of chronic antithrombotic treatment should be discussed with patients on an individual basis.

21. In cancer patients with concomitant DVT (especially axillary vein and more proximal veins), antithrombotic treatment should be initiated as soon as possible; preferred drugs include LMWHs (subunit 2.5.1) and fondaparinux (subunit 2.5.3) administered for at least three months (if there is no central catheter) or continuously (when there is still an inserted central catheter).

22. Some patients need thrombolytic drugs to maintain the central catheter in the vein (e.g. after symptoms intensification, when thrombus occludes the majority of the lumen of the subclavicular and axillary vein, symptoms sustain longer than 14 days, the patient is in good general state, expected survival time exceeds one year, and there is low bleeding risk).

\subsection{Treatment of cancer patients with VTE and concomitant thrombocytopaenia}

Venous thromboembolism can sometimes develop in cancer patients with concomitant thrombocytopaenia [96]. In order to establish optimal management, the following should be identified:

- cause of thrombocytopaenia (cancer infiltration of bone marrow, effect of chemotherapy, immunological thrombocytopaenia, drug-induced thrombocytopaenia, thrombotic microangiopathy, etc.);

- severity of thrombocytopaenia (no signs of haemorrhagic diathesis vs. bleeding);

- expected duration time of thrombocytopaenia (transient vs. long-term); 
- presence of additional (except thrombocytopaenia) risk factors of bleeding (older age, kidney and liver insufficiency, etc.).

The choice of antithrombotic treatment and its intensity in those cases should be based on individual assessment of potential benefits and disadvantages associated with the use of anticoagulants [13, 152-154].

\section{Guidelines:}

1. Use of therapeutic doses of antithrombotic drugs is recommended without transfusion of platelet concentrate if platelet counts in cancer patients with acute VTE episode are $\geq 50 \mathrm{G} / \mathrm{l}$ and there are no symptoms of haemorrhagic diathesis $[2 \mathrm{C}]$.

2. In cases of acute VTE episodes in cancer patient with platelet count $<50 \mathrm{G} / \mathrm{l}$ but without symptoms of haemorrhagic diathesis:

a. use of therapeutic doses of antithrombotic drugs is recommended with transfusion of platelet concentrate in order to maintain platelet count $\geq 50 \mathrm{G} / \mathrm{l}$. If it is impossible to maintain target platelet count, a decision about the use of therapeutic doses of antithrombotic drugs or their reduction should be based on individual assessment of potential benefits and disadvantages of particular therapeutic options $[2 \mathrm{C}]$;

b. if transfusion of platelet concentrate allows maintenance of platelet count in the range between 20-50 G/l, it is suggested to reduce the doses of antithrombotic drugs to $50 \%$ of therapeutic dose, but in clinically justified cases maintenance of therapeutic doses could be favourable $[2 \mathrm{C}]$;

c. if platelet count drops below $20 \mathrm{G} / \mathrm{l}$ despite transfusion of platelet concentrate, it is suggested to withdraw antithrombotic drugs [100] [2C].

3. In patients with limited clinical symptoms of haemorrhagic diathesis, without tendency to intensify during antithrombotic treatment, the above guidelines do not have to be modified.

4. In cases of acute VTE episodes in cancer patients with concomitant thrombocytopaenia and symptoms of haemorrhagic diathesis, it is suggested not to use antithrombotic drugs; however, the final decision should be based on individual assessment of potential benefits and disadvantages resulting from antithrombotic treatment or its discontinuation.

5. If transfusion of platelet concentrate is impossible or contraindicated and if there are significant clinical symptoms of haemorrhagic diathesis and acute episode of DVT of lower extremities could be life-threatening, implantation of a retrievable inferior vena cava filter should be considered in order to prevent PE. After resolution of contraindications to antithrombotic treatment the filter should immediately be removed and appropriate doses of antithrombotic drugs should be introduced. Literature data show that implantation of an inferior vena cava filter could cause poorer longterm prognosis (e.g. more frequent DVT recurrences) as compared to patients with VTE without filter implantation (these data are also relevant to cancer patients) [155-157]).

6. In the chronic treatment of cancer patients with concomitant thrombocytopaenia and VTE the following is suggested:

a. reduction of $\mathrm{LMWH}$ s doses by $50 \%$, if platelet count is in the range $25-50 \mathrm{G} / \mathrm{l}$ and there are no bleedings;

b. cessation of antithrombotic treatment if platelet count is $<25 \mathrm{G} / \mathrm{l}$ and/or there are significant symptoms of haemorrhagic diathesis [2C].

\subsection{Treatment of cancer patients with VTE and renal insufficiency}

The risk of bleeding complications in patients with renal insufficiency resulted from the use of therapeutic doses of LMWHs administered s.c. is two-fold higher as compare to patients with normal renal function [158]. There is a lack of data regarding accumulation of dalteparin. RCTs assessing the efficacy and safety of VTE treatment with DOAC included only $2.6-10 \%$ of cancer patients, and patients with eGFR $<50 \mathrm{ml} / \mathrm{min}$ accounted for only $7-21 \%$ of patients analysed in those trials. Elimination of DOAC through the kidneys is in the range between $80 \%$ (dabigatran) and $25 \%$ (apixaban); however, for rivaroxaban and edoxaban they are $33 \%$ and $35 \%$, respectively [159]. The usefulness of DOAC in the prevention and treatment of cancer patients with VTE and renal insufficiency was not assessed to date in RCTs. Guidelines regarding ESC in PE patients allows for the use of DOAC in eGFR $>30 \mathrm{ml} / \mathrm{min}$ if the bleeding risk in cancer patients is not high, which is associated with chronic treatment of VTE in patients with good prognosis. The majority of experts consider treatment with DOAC in cancer patients and renal insufficiency as not indicated $[8,104,153]$. Nevertheless, this is possible in carefully selected patients.

Renal insufficiency significantly increases the risk of VTE recurrence in cancer patients receiving antithrombotic drugs. In the CATCH study VTE recurrence during the first six months was detected in $14 \%$ of patients with eGFR $<60 \mathrm{ml} /$ min but only $8 \%$ in the remaining patients [160].

Guidelines [23, 104, 105, 153, 161, 162]:

1. In the initial treatment of cancer patients with VTE and renal insufficiency it is suggested to use intravenous UFH in therapeutic doses for 5-10 days with monitoring of APTT, which should be prolonged 1.5-2.5-fold as compare to baseline value. VKA could be introduced 
already on the first day together with UFH withdrawal, provided that INR is $>2$ for two consecutive days [2C].

2. Treatment with LMWHs with monitoring of anti-Xa activity could be an alternative option; however, optimal therapeutic concentration of LMWHs in this group of patients was not established to date. In patients without renal insufficiency treated with LMWHs, anti-Xa activity four hours after LMWH injection should account for $0.6-1.0 \mathrm{IU} / \mathrm{ml}$ during administration every 12 hours and $1.0-1.5 \mathrm{IU} / \mathrm{ml}$ during administration every 24 hours. Another option for patients treated with therapeutic doses of LMWHs and with eGFR $<30 \mathrm{ml} / \mathrm{min}$ is reduction of standard LMWH dose by $50 \%$ [2C].

3. In patients with end-stage renal disease during acute phase of VTE extracorporeal haemodialysis could be used in order to increase the safety of antithrombotic treatment. Indications to this procedure as well as doses of LMWH need to be established individually.

4. DOAC can be recommended only in selected cancer patients, with eGFR $>15 \mathrm{ml} / \mathrm{min}$ (minimal value for treatment with apixaban or rivaroxaban according to manufacturer's information), eGFR $>30 \mathrm{ml} / \mathrm{min}$ (minimal value for treatment with dabigatran), when administration of nephrotoxic drugs or drugs strongly influencing activity of cytochrome P450 (3A4) isoenzyme and P-glycoprotein is not planned, with exclusion of patients with intracranial tumour or tumour in other locations with bleeding risk, and in patients with thrombocytopaenia or liver injury [2C].

5. The decision about initiation of antithrombotic treatment in cancer patients with renal insufficiency needs to be individually assessed because there is increased risk of bleeding complications; however, in life-threatening situations, e.g. in patients with PE of high death risk, this indication is considered as relative.

6. In order to prevent recurrences it is recommended to use LMWHs for 3-6 months, and then VKA or LMWHs chronically or until cancer resolution $[2 \mathrm{C}]$.

\subsection{Treatment of pregnant women with coincidence of cancer and VTE}

In pregnant women with cancer and coincident VTE initial treatment is mainly based on LMWHs and UFH, which do not cross the placenta. Fondaparinux is not registered for the treatment during pregnancy, but during in vitro studies on experimental models it was indicated that it also does not cross the placenta [163]. The duration of VTE initial treatment is most commonly 5-7 days, but in selected cases, e.g. extensive thrombosis in iliofemoral part, prolongation of therapy up to two weeks could be considered (see below). Dosing of LMWHs and UFH during initial VTE treatment in pregnant women does not differ from treatment of other patient populations. In patients with renal insufficiency, in obese women, and in case of doubts regarding the efficacy and safety of LMWHs during pregnancy, serum anti-Xa activity should be measured four hours after last injection of the drug. When injections of therapeutic doses of LMWHs are administered every 12 hours the therapeutic value of anti-Xa should be within the range $0.6-1.0 \mathrm{IU} / \mathrm{ml}$, but when injected every 24 hours - 1.0-1.5 IU/ $\mathrm{ml}[164,165]$. Anti-Xa activity should also be assessed before the next dose of $\mathrm{LMWH}$; this is recommended in pregnant women with prosthetic heart valve, but could also be helpful in suspicion of standard dose failure.

Chronic treatment of pregnant women with cancer and after VTE episode should include UFH or LMWHs administered until the end of pregnancy and at least six weeks after the labour, altogether not shorter than six months. The daily dose of LMWHs in those cases should not be lower than $50 \%$ of the therapeutic dose. Some authors recommend continuation of LMWHs administered in therapeutic doses with anti-Xa activity measured every 1-3 months until the end of pregnancy. VKA are contraindicated during pregnancy; however, they could be used after giving birth by breast-feeding women as they are not excreted into human milk.

In order to reduce bleeding risk during delivery the last therapeutic dose of LMWH or UFH should be injected no later than 24-36 hours before planned induction of labour [101, 102]. Infusion of UFH should be finished 4-6 hours before planned delivery. If labour spontaneously starts during the full anticoagulation period central anaesthesia should be abandoned. In case of bleeding complications protamine sulphate should be used, which shows very high efficacy in reverse antithrombotic UFH effect, but significantly more weakly inhibits LMWHs. It should be also underlined that caesarean section increases the risk of VTE episode by two-fold as compare to natural delivery $[164,165]$. LMWHs should be restarted 12-24 hours after delivery and at least 12 hours after removal of the catheter for central anaesthesia, provided there are no bleeding complications.

Indications to thrombolytic treatment in pregnant women are the same as in other patients with acute VTE episode. Pregnancy is only a relative contraindication to thrombolysis in high-risk PE. Some clinicians consider that thrombolytic drugs could lead to placental abruption; however, there are no publications in scientific literature confirming this opinion [165].

Other methods of treatment of pregnant women with cancer and acute VTE episode include venous thrombectomy, implantation of an inferior vena cava filter in order to prevent $\mathrm{PE}$, and embolectomy of pulmonary artery. Indications to the mentioned procedures in pregnant women do not differ from indications in other groups of patients.

\section{Guidelines:}

1. Treatment of pregnant women with cancer and VTE should be conducted according the same rules as in other groups of patients [2C]. 
2. Both LMWHs and UFH can be used during pregnancy [2C].

3. VKA use is absolutely contraindicated during the first trimester of pregnancy and relatively contraindicated and discouraged during the second and third trimesters of pregnancy (except in women after implantation of a prosthetic heart valve) [2C].

4. Dosing of LMWHs and UFH during initial and chronic treatment of pregnant women with cancer and concomitant VTE is similar to dosing of those drugs in other groups of cancer patients and VTE. Measurement of anti-Xa activity is used for laboratory monitoring of therapeutic doses of LMWHs [2C].

5. Fondaparinux is allowed in pregnant women with HITT [2C].

6. Dosing of LMWHs and UFH has to be appropriately modified during delivery to minimise the risk of bleeding complications.

7. UFH, LMWHs, or VKA could be used during childbed (they are not excreted into human milk), but their choice is based on the clinical situation (e.g. modality of anticancer therapy) and the patient's preferences (influence of treatment on health-related quality of life, e.g. resulting from the need for frequent subcutaneous injections) [2C].

\subsection{Treatment of recurrent VTE during antithrombotic treatment}

Cancer patients receiving antithrombotic treatment also quite often have relapses of VTE [168-171]. However, there is lack of strong evidence allowing development of the guidelines. Cancer patients with VTE recurrence undergoing optimal antithrombotic treatment should be evaluated towards potential progression of malignant disease. In patients receiving LMWHs or UFH within the last 10-14 days it is also important to exclude HITT. Medical history regarding the patient's compliance and rigid taking of antithrombotic drugs should also be taken.

\section{Guidelines:}

1. In the case of VTE recurrence during treatment with LMWHs their dose could be increased by $20-25 \% \mathrm{IU} / \mathrm{ml}$ using measurement of maximal anti-Xa activity (1.6-2.0 IU/ $\mathrm{ml}$ during administration once daily, $0.8-1.0 \mathrm{lU} / \mathrm{ml}$ during administration twice daily), or fondaparinux therapy could be considered - longer than three months (in case of low or moderate bleeding risk) and up to three months when bleeding risk is high.

2. In case of VTE recurrence during VKA administration it is suggested to replace them with LMWHs or UFH s.c. (APTT 1.5-2.5 × control value).

\section{Using of antithrombotic treatment in order to prolong overall survival in cancer patients}

Available evidence from clinical trials does not justify use of antithrombotic drugs to prolong survival in cancer patients.

\section{References}

1. Lyman GH, Khorana AA, Wilmot JP. Cancer, clots and consensus: new understanding of an old problem. J Clin Oncol 2009; 27: 4821-4826.

2. Lee AY.Thrombosis in cancer: an update on prevention, treatment, and survival benefits of anticoagulants. Hematology Am Soc Hematol Educ Program 2010: 144-149.

3. Wojtukiewicz MZ, Sierko E. Zakrzepy a nowotwory. In: Windyga J, Pasierski T, Torbicki A (eds.). Zakrzepy i zatory. Wydanie I, Wydawnictwo Lekarskie PZWL, Warszawa 2014; 85-105.

4. Wojtukiewicz MZ, Sierko E. Powikłania zakrzepowo-zatorowe u chorych na nowotwory. In: Wojtukiewicz MZ, Deptała A (eds.). Problemy hematologiczne u chorych na nowotwory. Wydanie I. Termedia, Poznań 2014; 225-250.

5. Chew HK, Harvey D, Zhou H, White RH. Incidence of venous thromboembolism and its effect on survival among patients with common cancers. Arch Intern Med 2006; 166: 458-464.

6. Levitan N, Dowlati A, Remick SC et al. Rates of initial and recurrent thromboembolic disease among patients with malignancy versus those without malignancy: risk analysis using Medicare claims data. Medicine (Baltimore) 1999; 78: 285-291.

7. Mandala M, Reni M, Cascinu S et al. Venous thromboembolism predicts poor prognosis in irresectable pancreatic cancer patients. Ann Oncol 2007; 18: 1660-1665.

8. Lyman GH, Khorana AA, Kuderer NM et al. American Society of Clinical Oncology Clinical Practice. Venous thromboembolism prophylaxis and treatment in patients with cancer: American Society of Clinical Oncology clinical practice guideline update. J Clin Oncol 2013; 31:2189-2204.

9. Zacharski L, Costantini V, Wojtukiewicz MZ, Memoli VA, Kudryk BJ. Anticoagulants as anticancer therapy. Semin Oncol 1990; 17: 217-227.

10. Cohen AT, Tapson VF, Bergmann JF et al. Venous thromboembolism risk and prophylaxis in the acute hospital care setting (ENDORSE study): a multinational cross-sectional study. Lancet 2008; 371: 387-394.

11. Mandala M, Barni S, Florisani I et al. Incidence and clinical implications of venous thromboembolism in advanced colorectal cancer patients: the 'GISCAD-alternating schedule' study findings. Eur J Cancer 2009; 45: 65-73.

12. Timp JF, Braekkan SK, Versteeg HH, Cannegieter SC. Epidemiology of cancer-associated venous thrombosis. Blood 2013; 122: 1712-1723.

13. Farge $D$, Debourdeau $P$, Beckers $M$ et al. International clinical practice guidelines for the treatment and prophylaxis of venous thromboembolism in patients with cancer. J Thromb Haemost 2013; 11: 56-70.

14. Debourdeau $P$, Farge $D$, Beckers $M$ et al. International clinical practice guidelines for the treatment and prophylaxis of thrombosis associated with central venous catheters in patients with cancer. J Thromb Haemost 2013: $11: 71-80$.

15. Lyman GH, Khorana AA, Falanga A et al. American Society of Clinical Oncology American Society of Clinical Oncology guideline: recommendations for venous thromboembolism prophylaxis and treatment in patients with cancer. J Clin Oncol 2007; 25: 5490-5505.

16. Lyman GH, Kuderer NM, American Society of Clinical Oncology. Prevention and treatment of venous thromboembolism among patients with cancer: the American Society of Clinical Oncology Guidelines. Thromb Res 2010; 125 (Suppl 2): S120-S127.

17. Lyman GH, Bohlke K, Khorana AA et al. Venous thromboembolism prophylaxis and treatment in patients with cancer: American Society of Clinical Oncology Clinical Practice Guideline Update 2014. J Clin Oncol 2015; 33: 654-656.

18. Mandalà M, Falanga A, Roila F. ESMO Guidelines Working Group Management of venous thromboembolism (VTE) in cancer patients: ESMO Clinical Practice Guidelines. Ann Oncol 2011; 22 (Suppl 6): 85-92.

19. Streiff MB. National Comprehensive Cancer Center Network. The National Comprehensive Cancer Center Network (NCCN) guidelines on the management of venous thromboembolism in cancer patients. Thromb Res 2010; 125 (Suppl 2): S128-S133. 
20. Streiff MB, Bockenstedt PL, Cataland SR et al. National comprehensive cancer network. Venous thromboembolic disease. J Nat/ Compr Canc Netw 2013; 11: 1402-1429.

21. Antithrombotic Therapy and Prevention of Thrombosis, 9th ed: American College of Chest Physicians Evidence-Based Clinical Practice Guidelines. Chest 2012; 141 (Suppl 2): e419S-94S.

22. Kearon C, Akl EA, Ornelas J et al. Antithrombotic Therapy for VTE Disease: Chest Guideline, Chest 2016; 149: 315-352.

23. Zawilska K, Bała MM, Błędowski $P$ et al. Polish guidelines for the prevention and treatment of venous thromboembolism. 2012 update. Pol Arch Med Wewn 2012; 122 (Suppl 2): 3-74.

24. Tomkowski W et al. Profilaktyka i leczenie żylnej choroby zakrzepowo-zatorowej. Konsensus Polski - aktualizacja 2011. Acta Angiol 2011; 17 (Suppl A): 1-22.

25. Fijałkowska A, Szawłowski A, Wojtukiewicz M, Zawilska K. Rekomendacje Polskiego Towarzystwa Chirurgii Onkologicznej: Profilaktyka i przeciwzakrzepowe leczenie u pacjentów z nowotworami złośliwymi. Nowotwory J Oncol 2008; 1: 78-81.

26. Mandalà $M$, Falanga $A$, Piccioli $A$ et al. Venous thromboembolism and cancer: guidelines of the Italian Association of Medical Oncology (AIOM). Crit Rev Oncol Hematol 2006; 59: 194-204.

27. Farge D, Bosquet L, Kassab-Chahmi D et al. 2008 French national guidelines for the treatment of venous thromboembolism in patients with cancer: report from the working group. Crit Rev Oncol Hematol 2010; 73: 31-46.

28. Debourdeau P, Kassab Chahmi D, Le Gal G et al. French National Federation of Cancer Centers. 2008 SOR guidelines for the prevention and treatment of thrombosis associated with central venous catheters in patients with cancer: report from the working group. Ann Oncol 2009; 20: 1459-1457.

29. Konstantinides SV, Torbicki A, Agnelli G et al. Task force for the diagnosis and management of acute pulmonary embolism of the European Society of Cardiology. Eur Heart J 2014; 35: 3033-3069.

30. Nicolaides AN, Fareed J, Kakkar AK et al. Prevention and treatment of venous thromboembolism - International Consensus Statement. Int Angiol 2013; 32: 111-260.

31. Guyatt GH, Oxman AD, Kunz R et al. GRADE Working Group. Rating quality of evidence of and strength of recommandations. BMJ 2008; 336: 1049-1051.

32. Guyatt $\mathrm{GH}$, Oxman AD, Vist GE et al. GRADE Working Group. GRADE: an emerging consensus on rating quality of evidence and strength of recommendations. BMJ 2008; 336: 924-926.

33. Guyatt GH, Norris SL, Schulman S et al. American College of Chest Physicians. Methodology for the development of antithrombotic therapy and prevention of thrombosis guidelines: Antithrombotic Therapy and Prevention of Thrombosis, 9th ed: American College of Chest Physicians Evidence-Based Clinical Practice Guidelines. Chest 2012; 141 (Suppl 2): 53S-70S.

34. Windyga J, Podolak-Dawidziak M, Chojnowski K. Zasady rozpoznawania żylnej choroby zakrzepowo-zatorowej. Hematologia 2010; 1: 93-100.

35. Sørensen HT, Mellemkjaer L, Olsen JH, Baron JA. Prognosis of cancers associated with venous thromboembolism. N Engl J Med 2000; 343: 1846-1850.

36. Kahn SR, Springmann V, Schulman S et al. Management and adherence to VTE treatment guidelines in a national prospective cohort study in the Canadian outpatient setting. The Recovery Study. Thromb Haemost 2012; 108: 493-498.

37. Lee AY. Treatment of established thrombotic events in patients with cancer. Thromb. Res. 2012; 129 (Suppl 1): S146-S153.

38. den Exter PL, van der Hulle T, Lankeit M, Huisman MV, Klok FA. Long-term clinical course of acute pulmonary embolism. Blood Rev 2013; 27: 185-192.

39. Zawilska K. Profilaktyka i leczenie żylnych powikłań zakrzepowo-zatorowych u pacjentów z chorobą nowotworową. Hematologia 2014; 5: 228-238.

40. Raschke R, Hertel G. Clinical use of the heparin nomogram. Arch Intern Med 1991; 151: 2318-2321.

41. Decousus H, Tapson VF, Bergmann JF et al. Factors at admission associated with bleeding risk in medical patients. Chest 2011; 139: 69-79.

42. Cohen AT, Harrington R, Goldhaber SZ et al. The design and rationale for the Acute Medically III Venous Thromboembolism Prevention with Extended Duration Betrixaban (APEX) study. Am Heart J 2014; 167: 335-341.

43. Haddad TC, Greeno EW. Chemotherapy-induced thrombosis. Thromb Res 2006; 118: 555-568.
44. Che DH, Cao JY, Shang LH, Man YC, Yu Y. The efficacy and safety of low-molecular-weight heparin use for cancer treatment: a meta-analysis. Eur J Intern Med 2013; 24: 433-439.

45. Ben-Aharon I, Stemmer SM, Leibovici L, Shpilberg O, Sulkes A, Gafter-Gvili A. Low molecular weight heparin (LMWH) for primary thrombo-prophylaxis in patients with solid malignancies - systematic review and meta-analysis. Acta Oncol 2014; 53: 1230-1237.

46. AkI EA, Kahale L, Barba $M$ et al. Anticoagulation for the long-term treatment of venous thromboembolism in patients with cancer. Cochrane Database Syst Rev. 2014; 8: CD006650.

47. Di Nisio M, Porreca E, Otten HM, Rutjes AW. Primary prophylaxis for venous thromboembolism in ambulatory cancer patients receiving chemotherapy. Cochrane Database Syst Rev 2014; 29: CD008500.

48. Maraveyas A, Waters J, Roy R et al. Gemcitabine versus gemcitabine plus dalteparin thromboprophylaxis in pancreatic cancer. Eur J Cancer 2012; 48: 1283-1292.

49. Haas SK, Freund M, Heigener D et al. Low-molecular-weight heparin versus placebo for the prevention of venous thromboembolism in metastatic breast cancer or stage III/IV lung cancer. Clin Appl Thromb Hemost 2012; 18: 159-165.

50. Agnelli G, Gussoni G, Bianchini C et al. Nadroparin for the prevention of thromboembolic events in ambulatory patients with metastatic or locally advanced solid cancer receiving chemotherapy: a randomized, placebo-controlled, double-blind study. Lancet Oncol 2009; 10: 943-949.

51. Perry JR, Julian JA, Laperriere NJ et al. PRODIGE: a randomized placebo-controlled trial of dalteparin low-molecular-weight heparin thromboprophylaxis in patients with newly diagnosed malignant glioma. J Thromb Haemost 2010; 8: 1959-1965.

52. Verso M, Gussoni G, Agnelli G. Prevention of venous thromboembolism in patients with advanced lung cancer receiving chemotherapy: a combined analysis of the PROTECHT and TOPIC-2 studies. J Thromb Haemost 2010; 8: 1649-1651.

53. Larocca A, Cavallo F, Bringhen S et al. Aspirin or enoxaparin thromboprophylaxis for patients with newly diagnosed multiple myeloma treated with lenalidomide. Blood 2012; 119: 933-939.

54. Palumbo A, Cavo M, Bringhen S et al. Aspirin, warfarin, or enoxaparin thromboprophylaxis in patients with multiple myeloma treated with thalidomide: A phase III, open-label, randomized trial. J Clin Oncol 2011; 29: 986-993.

55. Riess H, Pelzer U, Opitz B et al. A prospective, randomized trial of simultaneous pancreatic cancer treatment with enoxaparin and chemotherapy: Final results of the CONKO-004 trial. J Clin Oncol 2010; 28: 15 (Suppl): 4033.

56. Riess H, Pelzer U, Deutschinoff G. PROSPECT-CONKO 004: a prospective randomized trial of simultaneous pancreatic cancer treatment with enoxaparin and chemotherapy. ASCO 2009: LBA4506.

57. Hu JC, Williams SB, O'Malley AJ et al. Androgen deprivation therapy for nonmetastatic prostate cancer is associated with an increased risk of peripheral arterial disease and venous thromboembolism. Eur Urol 2012; 61: 1119-1128.

58. Ehdaie B, Atoria CL, Gupta A et al. Androgen deprivation and thromboembolic events in men with prostate cancer. Cancer 2012; 118: 3397-3406.

59. Nalluri SR, Chu D, Keresztes R et al. Risk of venous thromboembolism with the angiogenesis inhibitor bevacizumab in cancer patients: a meta-analysis. JAMA 2008; 300: 2277-2285.

60. Hurwitz HI, Saltz LB, Van Cutsem E et al. Venous thromboembolic events with chemotherapy plus bevacizumab: a pooled analysis of patients in randomized phase II and III studies. J Clin Oncol 2011; 29: 1757-1764.

61. Carrier M, Le Gal G, Tay J et al. Rates of venous thromboembolism in multiple myeloma patients undergoing immunomodulatory therapy with thalidomide or lenalidomide: a systematic review and meta-analysis. JThromb Haemost 2011; 9: 653-663.

62. Terpos E, Kleber M, Engelhardt M et al. European Myeloma Network Guidelines for the management of multiple myeloma-related complications. Haematologica 2015; 100: 1254-1266.

63. Sierko E, Hempel D, Wojtukiewicz MZ. Powikłania hematologiczne u chorych poddawanych radioterapii. In: Wojtukiewicz MZ, Deptała A (ed.). Powikłania hematologiczne u chorych na nowotwory. Termedia, Poznań 2014: 171-190.

64. Meignan M, Rosso J, Gauthier $\mathrm{H}$ et al. Systematic lung scans reveal a high frequency of silent pulmonary embolism in patients with proximal deep venous thrombosis. Arch Intern Med 2000; 160: 159-164.

65. Cronin CG, Lohan DG, Keane M, Roche C, Murphy JM. Prevalence and significance of asymptomatic venous thromboembolic disease found on oncologic staging CT. AJR Am J Roentgenol 2007; 189: 162-170. 
66. Douma RA, Kok MG, Verberne LM, Kamphuisen PW, Büller HR. Incidental venous thromboembolism in cancer patients: prevalence and consequence. Thromb Res 2010; 125: e306-e309.

67. Ageno W, Squizzato A, Dentali F. Should the commonly accepted definition of "unprovoked venous thromboembolism" be revisited? Thromb Haemost 2012; 107: 806-807

68. Sahut D'Izarn M., Caumont Prim A., Planquette B. et al. Risk factors and clinical outcome of unsuspected pulmonary embolism in cancer patients: a case-control study. J. Thromb. Haemost 2012; 10: 2032-2038.

69. Shteinberg M, Segal-Trabelsy M, Adir Y, Laor A, Vardi M, Bitterman H. Clinical characteristics and outcomes of patients with clinically unsuspected pulmonary embolism versus patients with clinically suspected pulmonary embolism. Respiration 2012; 84: 492-500.

70. Dentali F, Ageno W, Giorgi Pierfranceschi M et al. Prognostic relevance of an asymptomatic venous thromboembolism in patients with cancer. J Thromb Haemost 2011; 9: 1081-1083.

71. Arnason T, Wells PS, Forster AJ. Appropriateness of diagnostic strategies for evaluating suspected venous thromboembolism. Thromb Haemost 2007; 97: 195-201.

72. Goekoop RJ, Steeghs N, Niessen RW et al. Simple and safe exclusion of pulmonary embolism in outpatients using quantitive D-dimer and Wells' simplified decision rule. Thromb Haemost 2007; 97: 146-150.

73. Guilabert JP, Manzur DN, Tarrasa MJ et al. Can multislice CT alone rule reliably embolism? A prospective study. Eur JRadiol 2007; 62: 220-226.

74. Castro DJ, Diaz G, Marti D et al. Monotherapy with enoxaparin for the prevention of recurrent venous thromboembolism. Blood Coagul Fibrinol 2007; 18: 173-177.

75. Tomkowski WZ, Davidson BL, Wiśniewska J et al. Accuracy of compression ultrasound In screening for deep vein thrombosis in acutely ill medical patients. Thromb Haemost 2007; 97: 191-194.

76. Monreal M, Lafoz E, Casals A et al. Occult cancer in patients with deep venous thrombosis. A systematic approach. Cancer 1991; 67: 541-545.

77. Trujillo-Santos J, Prandoni P, Rivron-Guillot K et al.; RIETE Investigators. Clinical outcome in patients with venous thromboembolism and hidden cancer: findings from the RIETE Registry. J Thromb Haemost 2008; 6: 251-255.

78. Gaitini DE, Brenner B. Do we need a cancer screening in patients with idiopathic deep vein thrombosis? Ultraschall Med 2008; 29 (Suppl 5): 220-225.

79. Ihaddadene R, Corsi DJ, Lazo-Langner A et al. Risk factors predictive of occult cancer detection in patients with unprovoked venous thromboembolism. Blood 2016; 127: 2035-2037.

80. Piccioli A, Lensing AW, Prins $\mathrm{MH}$ et al. SOMIT Investigators Group. Extensive screening for occult malignant disease in idiopathic venous thromboembolism: a prospective randomized clinical trial. J Thromb Haemost 2004; 2: 884-889.

81. Carrier M, Lazo-Langner A, Shivakumar S et al. Screening for occult cancer in unprovoked venous thromboembolism. N Engl J Med 2015; 373: 697-704.

82. Beckers MM, Schutgens RE, Prins $M H$, Biesma DH. Who is at risk for occult cancer after venous thromboembolism? J Thromb Haemost 2006; 4: 2731-2733.

83. Schutgens RE, Beckers MM, Haas FJ, Biesma DH. The predictive value of $D$-dimer measurement for cancer in patients with deep vein thrombosis. Haematologica 2005; 90: 214-219.

84. Paneesha S, Cheyne E, French K, Bacchu S, Borg A, Rose P. High D-dimer levels at presentation in patients with venous thromboembolism is a marker of adverse clinical outcomes. Br J Haematol 2006; 135: 85-90.

85. Rance A, Emmerich J, Guedj C, Fiessinger JN. Occult cancer in patients with bilateral deep-vein thrombosis. Lancet 1997; 350: 1448-1449.

86. Prandoni $P$, Lensing AW, Buller HR et al. Deep vein thrombosis and the incidence of subsequent symptomatic cancer. New Engl J Med 1992; 327: 1128-1133.

87. Samama MM, Cohen AT, Darmon JY et al. A comparison of enoxaparin with placebo for the prevention of venous thromboembolism in acutely ill medical patients. N Engl J Med 1999; 341: 793-800.

88. Leizorovicz A, Cohen AT, Turpie AG, Olsson CG, Vaitkus PT, Goldhaber SZ. PREVENT Medical Thromboprophylaxis Study Group. Randomized, placebo-controlled trial of dalteparin for the prevention of venous thromboembolism in acutely ill medical patients. Circulation 2004; 110: 874-879.

89. Cohen AT, Davidson BL, Gallus AS et al. Efficacy and safety of fondaparinux for the prevention of venous thromboembolism in older acute medical patients: randomized placebo controlled trial. BMJ 2006; 332: 325-329.
90. Barbar S, Noventa F, Rossetto $V$ et al. A risk assessment model for the identification of hospitalized medical patients at risk for venous thromboembolism: the Padua Prediction Score. J Thromb Hemost 2010; 8: 2450-2457.

91. Khorana AA, Kuderer NM, Culakova E, Lyman GH, Francis CW. Development and validation of a predictive model for chemotherapy-associated thrombosis. Blood 2008; 111: 4902-4907.

92. Agnelli G, Gussoni G, Bianchini $C$ et al. Nadroparin for the prevention of thromboembolic events in ambulatory patients with metastatic or locally advanced solid cancer receiving chemotherapy: a randomized placebo-controlled double-blind study. Lancet Oncol 2000; 10: 943-949.

93. Agnelli G, George DJ, Kakkar AK et al. Semuloparin for thromboprophylaxis in patients receiving chemotherapy for cancer. $N$ Engl J Med 2012; 366: 601-609.

94. Ay C, Dunkler D, Marosi $C$ et al. Prediction of venous thromboembolism in cancer patients. Blood 2010; 116: 5377-5382.

95. Lee AY, Kamphuisen PW. Epidemiology and prevention of catheter-related thrombosis in patients with cancer. J Thromb Haemost 2012; 10: 1491-1499.

96. Schiffer CA, Mangu PA, Wade JC et al. Central venous catheter care for the patient with cancer: American Society of Clinical Oncology Clinical Practice Guideline. J Clin Oncol 2013; 31: 1357-1370.

97. Mahan CE, Liu Y, Turpie $\mathrm{G}$ et al. External validation of a risk assessment model for venous thromboembolism in the hospitalized acutely-ill medical patient (VTE VALOURR). Thromb Haemost 2014; 112: 692-699.

98. Di Nisio M, Carrier M, Lyman GH, Khorana AA. Prevention of venous thromboembolism in hospitalized medical cancer patients: guidance from the SSC of the ISTH. J Thromb Haemost 2014; 12: 1746-1749.

99. Barsam SJ, Patel R, Arya R. Anticoagulation for prevention and treatment of cancer-related venous thromboembolism. Br J Haematol 2013; 161: 764-777.

100. Lee AYY, Peterson EA. Treatment of cancer-associated thrombosis. Blood 2013; 122: 2310-2317.

101. Windyga J. Powikłania zakrzepowo-zatorowe w chorobie nowotworowej. In: Krzakowski M, Warzocha K (ed.). Zalecenia postępowania diagnostyczno-terapeutycznego w nowotworach złośliwych 2013. Tom I. Onkol Prakt Klin 2013; 9 (Suppl B): 558-567

102. Windyga J. Powikłania zakrzepowo-zatorowe w chorobie nowotworowej - zasady postępowania w Instytucie Hematologii i Transfuzjologii. Hematologia 2013; 4: 56-64.

103. Windyga J. Profilaktyka i leczenie żylnej choroby zakrzepowo-zatorowej u pacjentów chorych na nowotwór złośliwy niepoddawanych operacjom chirurgicznym. Nowotwory J Oncol 2015; 65: 257-265.

104. Kahn SR, Lim W, Dunn A et al. Prevention of VTE in nonsurgical patients. Antithrombotic therapy and prevention of thrombosis, 9th ed: American College of Chest Physicians Evidence-Based Clinical Practice Guidelines. Chest 2012; 141 (Suppl 2): 195-226.

105. Polskie wytyczne profilaktyki i leczenia żylnej choroby zakrzepowo-zatorowej. Aktualizacja 2012. Medycyna Praktyczna 2012; wyd. specjalne.

106. Tassinari D, Santelmo C, Scarpi E et al. Controversial issues in thromboprophylaxis with low-molecular weight heparins in palliative care. J Pain Symptom Manage 2008; 36: e3-e4.

107. Soto-Cardenas MJ, Pelayo-Garcia G, Rodriguez-Camacho A et al. Venous thromboembolism in patients with advanced cancer under palliative care: additional risk factors, primary/secondary prophylaxis and complications observed under normal clinical practice. Palliat Med 2008; 22: 965-968.

108. Johnson M, Sproule M, Paul J. The prevalence and associated variables of deep venous thrombosis in patients with advanced cancer. Clin Oncol (R Coll Radiol) 1999; 11: 105-110.

109. Weber C, Merminod T, Herrmann FR et al. Prophylactic anti-coagulation in cancer palliative care: a prospective randomized study. Support Care Cancer 2008; 16: 847-852.

110. Holmes HM, Bain KT, Zalpour A, Luo R, Bruera E, Goodwin JS. Predictors of anticoagulation in hospice patients with lung cancer. Cancer 2010; 116: 4817-4824

111. Noble $\mathrm{S}$. The challenges of managing cancer related venous thromboembolism in the palliative care setting. Postgrad Med J 2007; 83: 671-674.

112. Noble SIR, Nelson A, Turner C, Finlay IG. Acceptability of low molecular weight heparin thromboprophylaxis for inpatients receiving palliative care: qualitative study. BMJ 2006; 332: 577-580.

113. Noble SI, Finlay IG. Have palliative care teams' attitudes toward venous thromboembolism changed? A survey of thromboprophylaxis practice across British specialist palliative care units in the years 2000 and 2005. J Pain Symptom Manage 2006; 32: 38-43. 
114. Bates SM, Greer IA, Middldorp S, Veenstra DL, Prabulous AM, Vandvik PO. VTE, thrombophilia, antithrombotic therapy and pregnancy. Chest 2012; 141 (Suppl 2): 691-736.

115. Marik PE, Plante LA. Venous thromboembolic disease and pregnancy. NEng/ J Med 2008; 359: 2025-2033.

116. Greer IA. Thrombosis in pregnancy: updates in diagnosis and management. Hematology Am Soc Hematol Educ Program 2012; 2012: 203-207.

117. AkI EA, Kahale L, Neumann I et al. Anticoagulation for the initial treatment of venous thromboembolism in patients with cancer. Cochrane Database Syst Rev 2014; 19: CD006649.

118. Cohen AT, Agnelli G, Anderson FA et al. VTE Impact Assessment Group in Europe (VITAE). Venous thromboembolism (VTE) in Europe. The number of VTE events and associated morbidity and mortality. Thromb Haemost 2007; 98: 756-764.

119. White RH. The epidemiology of venous thromboembolism. Circulation 2003: 107: 14-18.

120. Tomkowski WZ, Dybowska M, Kuca P et al. Effect of a public awareness campaign on the incidence of symptomatic objectively confirmed deep vein thrombosis: A controlled study. J Thromb Haemost 2012; 10: 2287-2290.

121. Hull RD, Pineo GF, Brant RF et al. Long-term low-molecular-weight heparin versus usual care in proximal — vein thrombosis patients with cancer. Am J Med 2006; 119: 1062-1072.

122. Meyer G, Marjanovic Z, Valcke J et al. Comparison of low molecular weight heparin and warfarin for the secondary prevention of venous thromboembolism in patients with cancer: a randomized controlled study. Arch Intern Med 2002; 162: 1729-1735.

123. Lee $\mathrm{AY}$, Levine MN, Baker RI et al. Randomized comparison of low-molecular-weight heparin versus oral anticoagulant therapy for the prevention of recurrent venous thromboembolism in patients with cancer (CLOT) investigators. Low molecular - weight heparin versus a coumarin for the prevention of recurrent venous thromboembolism in patients with cancer. NEngl J Med 2003; 349: 146-153.

124. Deitcher SR, Kessler CM, Merli G, Rigas JR, Lyons RM, Fareed J. ONCENOX Investigators. Secondary prevention of venous thromboembolic events in patients with active cancer: enoxaparin alone versus initial enoxaparin followed by warfarin for a 180-day period. Clin App/ Thromb Hemost 2006; 12: 389-396.

125. Romera A, Cairols MA, Vila-Coll $R$ et al. A randomised open-label trial comparing long-term subcutaneous low-molecular-weight heparin compared with oral-anticoagulant therapy in the treatment of deep venous thrombosis. Eur J Vasc Endovasc Surg 2009; 37: 349-356.

126. Lopez-Beret $\mathrm{P}$, Orgaz $A$, Fontcuberta J et al. Low molecular weight heparin versus oral anticoagulants in the long-term treatment of deep venous thrombosis. J Vasc Surg 2001; 33: 77-90.

127. Akl EA, Vasireddi SR, Gunukula $S$ et al. Anticoagulation for the initial treatment of venous thromboembolism in patients with cancer (Review). Cochrane Database Syst Rev 2011; 6: CD006649.

128. Hull RD, Pineo GF, Brant RF et al. Long-term low-molecular-weight heparin versus usual care in proximal-vein thrombosis patients with cancer. Am J Med 2006; 119: 1062-1072.

129. Hull RD, Pineo GF, Brant RF et al. Self-managed long-term low-molecular-weight heparin therapy: the balance of benefit and harms. Am J Med 2007; 120: 72-82.

130. Kakkar AK, Levine MN, Kadziola $Z$ et al. Low molecular weight heparin, therapy with dalteparin, and survival in advanced cancer: the fragmin advanced malignancy study (FAMOUS). J Clin Oncol 2004; 22: 1944-1948.

131. Klerk CP, Smorenburg SM, Otten HM et al. The effect of low molecular weight heparin on survival in patients with advanced malignancy. J Clin Oncol 2005; 23: 2130-2135.

132. Altinbas $\mathrm{M}$, Coskun $\mathrm{HS}, \mathrm{Er} \mathrm{O}$ et al. A randomized clinical trial of combination chemotherapy with and without low molecular-weight heparin in small cell lung cancer. J Thromb Haemost 2004; 2: 1266-1271.

133. Sideras K, Schaefer PL, Okuno SH et al. Low-molecular weight heparin in patients with advanced cancer: a phase 3 clinical trial. Mayo Clin Proc 2006; 81: 758-767.

134. Krauth $D$, Holden $A$, Knapic $N$ et al. Safety and efficacy of long-term oral anticoagulation in cancer patients. Cancer 1987; 59: 983-985.

135. Holbrook A, Schulman S, Witt DM. et al. Evidence-based management of anticoagulant therapy: Antithrombotic therapy and prevention of thrombosis, $9^{\text {th }}$ ed: ACCP evidence-based clinical practice guidelines. Chest 2012; 141 (Suppl 2): 152-184.

136. Kearon C, Akl EA, Comerota AJ et al. Antithrombotic therapy for VTE Disease: Antithrombotic therapy and prevention of thrombosis, $9^{\text {th }}$ ed: ACCP evidence-based clinical practice guidelines. CHEST 2012; 141 (Suppl 2): 419-494.

137. Gladish GW, Choe DH, Marom EM, Sabloff BS, Broemeling LD, Munden RF. Incidental pulmonary emboli in oncology patients: prevalence, CT evaluation, and natural history. Radiology 2006; 240: 246-255.

138. Louzada ML, Majeed H, Wells PS. Efficacy of low-molecular-weight-heparin versus vitamin $\mathrm{K}$ antagonists for long term treatment of cancer-associated venous thromboembolism in adults: a systematic review of randomized controlled trials. Thromb Res 2009; 123: 837-844.

139. Francis CW, Kessler CM, Goldhaber SZ et al. Treatment of venous thromboembolism in cancer patients with dalteparin for up to 12 months: the DALTECAN Study. J Thromb Haemost 2015; 13: 1028-1035.

140. Louzada ML. Predicting venous thromboembolism recurrence risk in patients with cancer. A validation study. Blood 2012; 120: 394

141. Chee $C E$, Ashrani AA, Marks RS et al. Predictors of venous thromboembolism recurrence and bleeding among active cancer patients: a population based cohort study. Blood 2014; 123: 3972-3978.

142. Ferretti G, Bria $E$, Giannarelli $D$ et al. Is recurrent venous thromboembolism after therapy reduced by low-molecular-weight heparin compared with oral anticoagulants? Chest 2006; 130: 1808-1816.

143. Brighton TA, Eikelboom JW, Mann K et al. Low-dose aspirin for preventing recurrent venous thromboembolism. N Engl J Med 2012; 367: 1979-1987.

144. Becattini C, Agnelli G, Schenone A et al. Aspirin for preventing the recurrence of venous thromboembolism. NEnglJMed 2012;367: 1959-1967.

145. Larsen TB, Nielsen PB, Skjøth F, Rasmussen LH, Lip GY. Non-vitamin K antagonist oral anticoagulants and the treatment of venous thromboembolism in cancer patients: a semi systematic review and meta-analysis of safety and efficacy outcomes. PLoS One 2014; 9: e114445.

146. van der Hulle T, den Exter PL, Kooiman J, van der Hoeven Juisman MV, Klok FA. Meta-analysis of the efficacy and safety of new oral anticoagulants in patients with cancer-associated acute venous thromboembolism. J Thromb Haemost 2014; 12: 1116-1120.

147. Short NJ, Connors JM. New oral anticoagulants and the cancer patient. The Oncologist 2014; 19: 82-93.

148. EINSTEIN Investigators. Oral rivaroxaban for symptomatic venous thromboembolism. N Eng/ J Med 2010; 363: 2499-2510.

149. EINSTEIN-PE Investigators. Oral rivaroxaban for the treatment of symptomatic pulmonary embolism. NEnglJMed 2012; 366: 1287-1297.

150. Tomkowski W, Chmielewski D, Gaciong Z et al. Wytyczne postepowania w nagłych i planowych sytuacjach klinicznych, mogących zaistnieć u chorych leczonych doustnymi, bezpośrednimi inhibitorami aktywnego czynnika X oraz aktywnego czynnika II. Acta Angiologica 2012; 18: 40-49.

151. Agnelli G, Buller HR, Cohen A et al. Apixaban for extended treatment of venous thromboembolism. NEngl J Med 2013; 368: 699-708.

152. Carrier M, Khorana AA, Zwicker Jl et al. Management of challenging cases of patients with cancer-associated thrombosis including recurrent thrombosis and bleeding: guidance from the SSC of the ISTH. J Thromb Haemost 2013; 11: 1760-1765.

153. Tagalakis V, Wharin C, Kahn SR. Comprehensive update on the prevention and treatment of venous thromboembolism in cancer patients. Semin Thromb Hemost 2013; 39: 127-140.

154. Prandoni P, Samama MM. Risk stratification and venous thromboprophylaxis in hospitalized medical and cancer patients. Br J Haematol 2008; 141: 587-597.

155. Schleich JM, Morla O, Laurent M, Langella B, Chaperon J, Almange C. Long-term follow-up of percutaneous vena cava filters: a prospective study in 100 consecutive patients. Eur JVasc Endovasc Surg 2001; 21:450-457.

156. Jarrett BP, Dougherty MJ, Calligaro KD. Inferior vena cava filters in malignant disease. J Vasc Surg 2002; 36: 704-707.

157. Wallace MJ, Jean $\mathrm{JL}$, Gupta $\mathrm{S}$ et al. Use of inferior vena caval filters and survival in patients with malignancy. Cancer 2004; 101: 1902-1907.

158. Siguret V, Gouin-Thibault I, Pautas E et al. No accumulation of the peak anti-factor Xa activity of tinzaparin in elderly patients with moderate-to severe renal impairment: The IRIS substudy. J Thromb Haemost 2011; 9: 1966-1972.

159. Lega JC, Bertoletti L, Gremilet $C$ et al. Consistency of safety profile of new oral anticoagulants in patients with renal failure. J Thromb Haemost 2014; 12: 337-343.

160. Hillis CM, Crowther MA. Acute phase treatment of VTE: Anticoagulation, including non-vitamin $\mathrm{K}$ antagonis oral anticoagulants. Thromb Haemost 2015; 114: 1193-1202.

161. Short NJ, Connors JM. New oral anticoagulants and the cancer patient. The Oncologist 2014; 19: 82-93. 
162. Van der Hulle T, den Exter PL, Kooiman J et al. Meta-analysis of efficacy and safety of new oral anticoagulants in patients with cancer-associated acute venous thromboembolism. J Thromb Haemost 2014; 12: 1116-1120.

163. Dempfle CEH. Minor transplacental passage of fondaparinux in vivo. NEngl J Med 2004; 350: 1914-1915.

164. Chan WS, Ginsberg JS. Management of venous thromboembolism in pregnancy. In: van Beek EJR, Büller HR, Oudkerk M (ed.). Deep vein thrombosis and pulmonary embolism. Wiley-Blackwell, ChiChester 2009: 353-371.

165. Bates SM, Greer IA, Pabinger I, Sofaer S, Hirsh J. Venous thromboembolism, thrombophilia, antithrombotic therapy and pregnancy: American College of Chest Physicians evidenced-based clinical practice guidelines ( $8^{\text {th }}$ edition). Chest 2008; 133: 844-886.

166. Bates SM, Ginsberg JS. How we manage venous thromboembolism during pregnancy. Blood 2002; 100: 3470-3478.
167. Lim W, Dentali F, Eikelboom JW et al. Meta-analysis: Low-molecular-weight heparin and bleeding in patients with severe renal insufficiency. Ann Intern Med 2006; 144: 673-684.

168. Zawilska K. Żylna choroba zakrzepowo-zatorowa. In: Jędrzejczak WW, Robak T, Podolak-Dawidziak M (ed). Praktyka hematologiczna praca zbiorowa. Termedia, Poznań 2015: 569-586.

169. Zawilska K. Żylna choroba zakrzepowo-zatorowa. In: RobakT, Warzocha K (ed). Hematologia. Wydawnictwo Via Medica, Gdańsk 2016: 507-521.

170. Podolak-Dawidziak M, Usnarska-Zubkiewicz L. Zakrzepowe powikłania leczenia przeciwnowotworowego. In: Jędrzejczak WW, Robak T, Podolak-Dawidziak M (ed). Praktyka hematologiczna praca zbiorowa. Termedia, Poznań 2015: 625-629.

171. Undas A, Zawilska K. Ogólne zasady leczenia przeciwkrzepliwego. In Gajewski P (ed). Interna Szczeklika. Podręcznik chorób wewnętrznych. Wydawnictwo Medycyna Praktyczna, Kraków 2015: 539-553. 